\title{
Different shapes of $\mathrm{Fe}_{3} \mathrm{O}_{4}$ nanoparticles on the free convection and entropy generation in a wavy- wall square cavity filled by power-law non-Newtonian nanofluid
}

\author{
Mohammad Hatami \\ Department of Mechanical Engineering, Esfarayen University of Technology (EUT), Esfarayen 9661998195, North Khorasan, \\ Iran
}

Corresponding author Email: m.hatami@xjtu.edu.cn

https://doi.org/10.18280/ijht.360215

Received: 13 September 2017

Accepted: 20 March 2018

\section{Keywords:}

nanofluid, Entropy generation, wavy cavity, natural convection, nonNewtonian

\begin{abstract}
The goal of this paper is to investigate the influences of Nanoparticles volume fraction, Nanoparticles shape, amplitude and wavelength of wavy surface, Hartmann number and the Angle of magnetic field on the Nusselt number, Bejan number and the entropy generation rate in a wavy wall cavity, numerically. The nanoparticles are considered $\mathrm{Fe}_{3} \mathrm{O}_{4}$ which are magnetic in presence of magnetic and the base fluid is considered as a power-law non-Newtonian nanofluid which its density variation is approximated by the standard Boussinesq model. The wavy wall is maintained in low temperatures while the right wall has high temperature and up/down walls is insulated. The problem is solved by finite element method using FlexPDE commercial code and found that the highest average Nusselt number is observed for the Nanofluid with brick shaped particles; however, the Nanofluid with spherical shaped particles is found to have the lowest Nusselt. Furthermore, Minimum and maximum Bejan numbers were observed for brick and spherical nanoparticles, respectively.
\end{abstract}

\section{INTRODUCTION}

The interesting concept of convection flow in a cavity with horizontally sliding walls are mostly designed to simulate lubrication problems, develop new techniques of electronic cooling and they even have been found to be useful for some applications in the field of engineering [1-5]. Here some of these valuable studies are reviewed. Mohyud-Din et al. [6] in an analytical study, considered the three dimensional heat and mass transfer with magnetic effects for the flow of a nanofluid between two parallel plates in a rotating system. As one of their main outcomes, thermophoresis and Brownian motion parameters are directly related to heat transfer but are inversely related to concentration profile. Khan et al. [7] computed and examined the effects of different parameters on the velocity, temperature, skin friction coefficient and Nusselt number of nanofluid flow.

Once used for heat transfer purposes, conventional fluids for example water, ethylene glycol, and oils are proved to have a rather lower thermal conductivity than many of so called Nanofluids. These are fluids with certain amount of metal nanoparticles in them, to which researchers have increasingly grown interest regarding their potential use for heat transfer without inducing significant drop in the pressure [8-14]. Milani Shirvan et al. [8-10] simulated the nanofluid heat transfer in pipe, heat exchangers aand solar cavities using finite volume method (FVM). Fakour et al. [11] used the weighted residual methods and Ghasemi et al. [12] used efficient analytical methods for the nanofluid modeling. To optimize the results of the modeling, Rahimi-Gorji et al. [13] and Mamourian et al. [14] applied the Response Surface Methodology (RSM) on the obtained results. Versus the most studies presented here, Kefayati [15] modeled the nonNewtonian nanofluid flow in a square cavity and investigated the power law index on the viscosity on the results.

One of the recent works on the use of Nanofluid as a heat transfer medium in the major context of mixed heat transfer is that of Shermet and Pop [16]. They tried to numerically simulate the Nanofluid mixed convection in a lid driven box cavity utilizing Buongiorno's model. A few variables as an example the Grashof, Reynolds, Lewis and the Prandtl numbers, Brownian motion, Thermophoresis, Buoyancy ratio and the moving variables on the mean and local Nusselt numbers and the mean and local Sherwood numbers were studied in this paper. Another research which investigated heat transfer characteristics in a lid driven cavity has been done by Ghaffarpasand [17]; he investigated the impact of Joule heating and Lorenz force on MHD natural convection in a Nanofluid filled lid driven cavity. The Nanofluid in this numerical experiment was water containing $\mathrm{Fe} 3 \mathrm{O} 4$ particles. He found that increasing each or both Hartmann or Eckert numbers would result in reduced heat transfer rate. Hussain et al. [18] surveyed the entropy generation rate in a double lid driven Nanofluid filled cavity. In this numerical modeling the cavity was partially heated and under an inclined magnetic field. In a further study, Hussain et al. [19] studied the impact of the magnetic field inclination angle changes on heat transfer. Modeling conditions were the same as their previous numerical study [18] and heat transfer parameters including the mean Nusselt number, entropy generated rate by heat transfer, total entropy generation, Bejan number, Kinetic energy, fluid friction and magnetic field were calculated against different inclination angles. A quite interesting 3-D numerical modeling of heat transfer was held by Ghachem et al. [20]. They have successfully tried to calculate local and mean Nusselt numbers and Sherwood number. They have also presented particle trajectories, isotherms and isoconcentrations. Rahmati [21] considered the mixed convection 
heat transfer of water with $\mathrm{Cu}$ particles as Nanofluid in a double lid-driven cavity, modeled by Lattice Boltzmann method. He has concluded that for all thermal phase deviations, heat transfer and Nusselt number would enhance as the Richman number decreases. In a similar study by Jmai et al. [22] the effect of different walls velocity ratios on heat transfer were investigated. They modeled a double lid driven Nanofluid filled cavity and impose partial heating to analyze mixed convection. They found that adding Nanoparticles would indeed increase the heat transfer, which would be accentuated as the Richardson number is reduced. Kareem et al. [23] used a 2-D model to numerically investigate mixed convection in a trapezoidal cavity filled with different Nanofluids. Cheng and Liu [24] modeled a lid driven filled with air cavity to study the impact of cavity inclination angle, Richardson number and aspect ratio on heat transfer. They deduced that with a flow in the dominated regime of forced convection, heat transfer was not affected by the inclination angle. Ismael et al. [25] numerically modeled a lid driven partial slip square cavity. The results suggested that the convection parameters would decline at certain critical values of partial slip parameters. Another useful work is that of Muthtamilselvan and Doh [26] through which they have modeled mixed convection in a square lid driven cavity that contained water and $\mathrm{Cu}$ particles as Nanofluid with nonuniform and uniform heated bottom wall. There have been many other researches on the Nanofluid such as Refs. [27-34]. Some other studies on the entropy generation and flows with heat transfer, which we regard them as natural and forced convection, could be found in the works of Haddad et al. [31], Khalkhali et al. [32], Abu-Hijleh et al. [33], Abu-Hijleh and Heilen [34] and Mahmud and Island [35].

This brief explore through the literature shows that there have been a lot of researches on the natural convection, especially modeled Newtonian fluid in the square cavities, but the study of wavy wall and non-Newtonian nanofluid has been less appealing to the researchers. Hence we presume it is useful to study the effective parameters of which the natural heat transfer rate is most likely affected, with considering the total entropy generation rate $\left(\mathrm{S}_{\mathrm{S}}^{*}\right)$, mean Nusselt number $(\mathrm{Nu})$ and Bejan number. The geometry of the model is a square cavity. It's fully insulated bottom and top walls, the right side wall of the cavity is fixed in place and assumed to remain at a fixed hot temperature during the investigation. The Left side wall is a wavy surface and imposes a cold temperature. These parameters are to be recorded as the results of this numerical analysis: the $\mathrm{Fe}_{3} \mathrm{O}_{4}$ Nanoparticles volume fraction, amplitude of the wavy surface through the left wall and the Hartmann number and angle of magnetic field. Also, it is reported the so far less investigated Nanoparticles shape impact on the entropy generation rate and heat transfer.

\section{PROBLEM STATEMENT}

Fig. 1 indicates the geometry of the studied wavy wall square cavity. The left wavy-walled is in cold temperature (TL) and a constant hot temperature (TH) is applied to the right flat wall. Two insulated bottom and upper flat walls are considered fixed in their position. The cavity is filled with a nonNewtonian shear-thinning nanofluid of $\mathrm{Fe}_{3} \mathrm{O}_{4}$ /non-Newtonian in the presence of a magnetic field where the pertinent thermophysical properties are given in Table 1 . A magnetic field with angle $\left(\gamma=0,30\right.$ and $\left.60^{\circ}\right)$ has been applied on the flow. The flow is incompressible, steady, and laminar. The density variation is approximated by the standard Boussinesq model. A non-dimensional cosine function is used to simulate the wavy wall as shown on figure where Am is the wave amplitude.

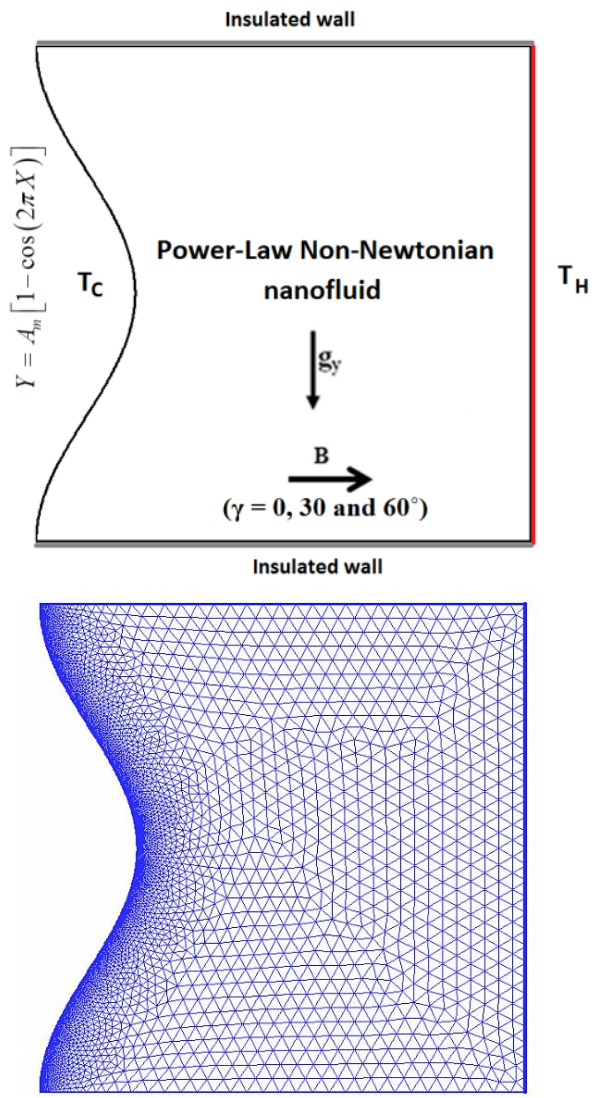

Figure 1. Schematic of the wavy wall square cavity and generated mesh

Table 1. Thermo-physical properties of nanoparticles

\begin{tabular}{cccccc}
\hline & $\boldsymbol{\rho}$ & $\mathbf{C}_{\mathbf{p}}$ & $\mathbf{k}$ & $\boldsymbol{\beta}$ & $\boldsymbol{\sigma}$ \\
\hline $\mathrm{Fe}_{3} \mathbf{O}_{4}$ & 5200 & 670 & 6 & $1.3 \times 10^{-5}$ & 25000 \\
\hline
\end{tabular}

\section{MATHEMATICAL MODELING}

In this study, the temperature and velocity fields in wavy square cavity of Fig. 1 are obtained utilizing the continuity, Navier-Stokes and energy equations. Therefore, the governing equations simplicity is performed considering the following assumptions:

-The flow is incompressible and Nanofluid is power-law non-Newtonian

- There is no relative movement between fluid and $\mathrm{Fe} 3 \mathrm{O} 4$ particles and thermal equilibrium exists between them.

- The temperature and velocity fields are laminar, steady state and 2-D.

-The effects of radiation and viscous dissipation are neglected.

\subsection{Governing equation of heat and mass transfer}

The governing equations (continuity, momentum and energy equations) and definition of dimensionless variables can be derived as follows based on above assumptions [15]. 
$\frac{\partial v}{\partial y}+\frac{\partial u}{\partial x}=0$

$\left(v \frac{\partial u}{\partial y}+u \frac{\partial u}{\partial x}\right)=\frac{1}{\rho_{n f}}\left[\begin{array}{c}-\frac{\partial P}{\partial x}+\mu_{n f}\left(\frac{\partial^{2} u}{\partial x^{2}}+\frac{\partial^{2} u}{\partial y^{2}}\right)+ \\ \sigma_{n f} B^{2}\left(v \sin \gamma \cos \gamma-u \sin ^{2} \gamma\right)\end{array}\right]$

$\left(v \frac{\partial v}{\partial y}+u \frac{\partial v}{\partial x}\right)=\frac{1}{\rho_{n f}}\left[\begin{array}{l}-\frac{\partial P}{\partial y}+\mu_{n f}\left(\frac{\partial^{2} v}{\partial x^{2}}+\frac{\partial^{2} v}{\partial y^{2}}\right)+g \rho_{n f} \beta_{n f}\left(T-T_{c}\right)+ \\ \sigma_{n f} B^{2}\left(u \sin \gamma \cos \gamma-v \cos ^{2} \gamma\right)\end{array}\right]$

$\left(\rho C_{p}\right)_{n f}\left(v \frac{\partial T}{\partial y}+u \frac{\partial T}{\partial x}\right)=k_{n f}\left(\frac{\partial^{2} T}{\partial x^{2}}+\frac{\partial^{2} T}{\partial y^{2}}\right)$

Additionally, in order to dissolve the governing equations, the Nanofluid effective properties are needed, which are given as

$\rho_{n f}=\rho_{s} \phi+\rho_{f}(1-\phi)$

$\left(\rho C_{P}\right)_{n f}=\left(\rho C_{P}\right)_{s} \phi+\left(\rho C_{P}\right)_{f}(1-\phi)$

$\alpha_{n f}=\frac{k_{n f}}{\left(\rho C_{P}\right)_{n f}}$

$\beta_{n f}=\beta_{f}(1-\phi)+\beta_{s} \phi$

$\mu_{n f}=\frac{\mu_{f}}{(1-\phi)^{2.5}}$

$\frac{\sigma_{n f}}{\sigma_{f}}=1+\frac{3\left(\frac{\sigma_{s}}{\sigma_{f}}-1\right) \phi}{\left(\frac{\sigma_{s}}{\sigma_{f}}+2\right)-\left(\frac{\sigma_{s}}{\sigma_{f}}-1\right) \phi}$

$\mu_{f}=N\left\{2\left(\frac{\partial u}{\partial x}\right)^{2}+2\left(\frac{\partial v}{\partial x}\right)^{2}+\left(\frac{\partial v}{\partial y}+\frac{\partial u}{\partial x}\right)^{2}\right\}^{\frac{(n-1)}{2}}$

For all the nanoparticles, the Hamilton equation is used to calculate the thermal conductivity of nanofluid

$$
\frac{k_{n f}}{k_{f}}=\frac{k_{p}+(m+1) k_{f}-(m+1) \varphi\left(k_{f}-k_{p}\right)}{k_{p}+(m+1) k_{f}+\varphi\left(k_{f}-k_{p}\right)}
$$

Here, for spherical nanoparticles $m=3$. For other nanoparticles shape, $\mathrm{m}$ can be calculated from following equation and Table 2.

Table 2. Constant of Eq. (13)

\begin{tabular}{cc}
\hline Nanoparticle Shape & $\boldsymbol{\psi}$ \\
\hline Spherical & 1 \\
Platelet & 0.52 \\
Cylindrical & 0.62 \\
Brick & 0.81 \\
\hline
\end{tabular}

$m=\frac{3}{\psi}$

$\mathrm{N}$ is the consistency coefficient and $\mathrm{n}$ is the power-law index. Therefore, the deviation of $\mathrm{n}$ from unity indicates the degree of deviation from Newtonian behavior. With $\mathrm{n} \neq 1$, the constitute Eq. (11) represents pseudo plastic fluid $(n<1)$ and for $(n>1)$ it represents a dilatant fluid, respectively.

Boundary condition of the problem is:

$\left\{\begin{array}{lll}\text { Insulated walls: } & u=v=0, & \frac{\partial T}{\partial y}=0 \\ \text { Wavy wall: } & u=v=0, & T=T_{c} \\ \text { Right wall: } & u=v=0, & T=T_{H}\end{array}\right.$

The following dimensionless variables are introduced:

$$
\begin{aligned}
& \mathrm{T}=\frac{T-T_{C}}{T_{H}-T_{C}}, U=\frac{u L}{\alpha_{f} R a^{0.5}}, V=\frac{v L}{\alpha_{f} R a^{0.5}}, \\
& Y=\frac{y}{L}, \mathrm{X}=\frac{x}{L}, P=\frac{p L^{2}}{\rho_{f}\left(\alpha_{f}\right)^{2} R a},
\end{aligned}
$$

Using Eq. (15), Eqs, (1)-(4) can be written in dimensionless form as

$$
\frac{\partial V}{\partial Y}+\frac{\partial U}{\partial X}=0
$$

With dimensionless parameters

$$
\begin{aligned}
V \frac{\partial U}{\partial Y}+U \frac{\partial U}{\partial X}= & -\frac{\partial P}{\partial X}+\frac{\operatorname{Pr}}{\sqrt{R a}} \frac{\rho_{f}}{\rho_{n f}} \frac{1}{(1-\varphi)^{2.5}}\left[2 \frac{\partial}{\partial X}\left(\frac{\mu_{f}}{N} \frac{\partial U}{\partial X}\right)+\frac{\partial}{\partial Y}\left(\frac{\mu_{f}}{N}\left(\frac{\partial U}{\partial Y}+\frac{\partial V}{\partial X}\right)\right)\right] \\
& +\frac{H a^{2} \operatorname{Pr}}{\sqrt{R a}}\left[\frac{\sigma_{n f} / \sigma_{f}}{\rho_{n f} / \rho_{f}}\right] \frac{1}{(1-\varphi)^{2.5}}\left(V \sin \gamma \cos \gamma-U \sin ^{2} \gamma\right),
\end{aligned}
$$

$$
\begin{aligned}
V \frac{\partial V}{\partial Y}+U \frac{\partial V}{\partial X}= & -\frac{\partial P}{\partial Y}+\frac{\operatorname{Pr}}{\sqrt{R a}} \frac{\rho_{f}}{\rho_{n f}} \frac{1}{(1-\varphi)^{2.5}}\left[2 \frac{\partial}{\partial Y}\left(\frac{\mu_{f}}{N} \frac{\partial V}{\partial Y}\right)+\frac{\partial}{\partial X}\left(\frac{\mu_{f}}{N}\left(\frac{\partial U}{\partial Y}+\frac{\partial V}{\partial X}\right)\right)\right] \\
& +\frac{H a^{2} \operatorname{Pr}}{\sqrt{R a}}\left[\frac{\sigma_{n f} / \sigma_{f}}{\rho_{n f} / \rho_{f}}\right] \frac{1}{(1-\varphi)^{2.5}}\left(U \sin \gamma \cos \gamma-V \cos ^{2} \gamma\right)+\operatorname{Pr} \frac{(\rho \beta)_{n f}}{\rho_{n f} \beta_{f}} T
\end{aligned}
$$

$U \frac{\partial \mathrm{T}}{\partial X}+V \frac{\partial \mathrm{T}}{\partial Y}=\frac{1}{\sqrt{R a}}\left[\frac{\frac{k_{n f}}{k_{f}}}{\frac{\left(\rho C_{p}\right)_{n f}}{\left(\rho C_{p}\right)_{f}}}\right]\left(\frac{\partial^{2} \mathrm{~T}}{\partial X^{2}}+\frac{\partial^{2} \mathrm{~T}}{\partial Y^{2}}\right)$

$R a_{f}=\frac{\rho_{f} \beta_{f} g L^{3}\left(T_{H}-T_{C}\right)}{\left(\alpha_{f} \mu_{f}\right)}, \operatorname{Pr}=\frac{v_{f}}{\alpha_{f}}, H a=L B \sqrt{\frac{\sigma_{f}}{\mu_{f}}}$,

$\left\{\begin{array}{lll}\text { Insulated walls: } & U=V=0, & \frac{\partial T}{\partial Y}=0 \\ \text { Wavy wall: } & U=V=0, & T=0 \\ \text { Right wall: } & U=V=0, & T=1\end{array}\right.$

\subsection{Entropy generation}

In the studied problem, the irreversibility is generated 
through heat transfer, fluid flow and magnetic field. As a result, the total entropy is the sum of irreversibilities due to thermal gradients, viscous dissipation and the magnetic field as follows [15]

$$
S_{S}=S_{F}+S_{T}+S_{G}
$$

where the entropy generations due to fluid flow (SF), the magnetic field (SG) and heat transfer (ST) are calculated as follows

$$
\begin{aligned}
& S_{F}=\frac{\mu_{n f}}{T_{0}}\left[2\left(\frac{\partial u}{\partial x}\right)^{2}+2\left(\frac{\partial v}{\partial x}\right)^{2}+\left(\frac{\partial v}{\partial y}+\frac{\partial u}{\partial x}\right)^{2}\right] \\
& S_{T}=\frac{k_{n f}}{T_{0}^{2}}\left[\left(\frac{\partial T}{\partial x}\right)^{2}+\left(\frac{\partial T}{\partial y}\right)^{2}\right] \\
& S_{G}=\frac{\sigma_{n f} B^{2}}{T_{0}}(u \sin \gamma-v \cos \gamma)^{2}
\end{aligned}
$$

An important measure of the entropy field is Bejan number (Be) which is defined as the ratio between entropy generations due to heat transfer irreversibilities to the total entropy generation as follow

$B e=\frac{S_{T}}{S_{S}}$

In non-dimensional shape
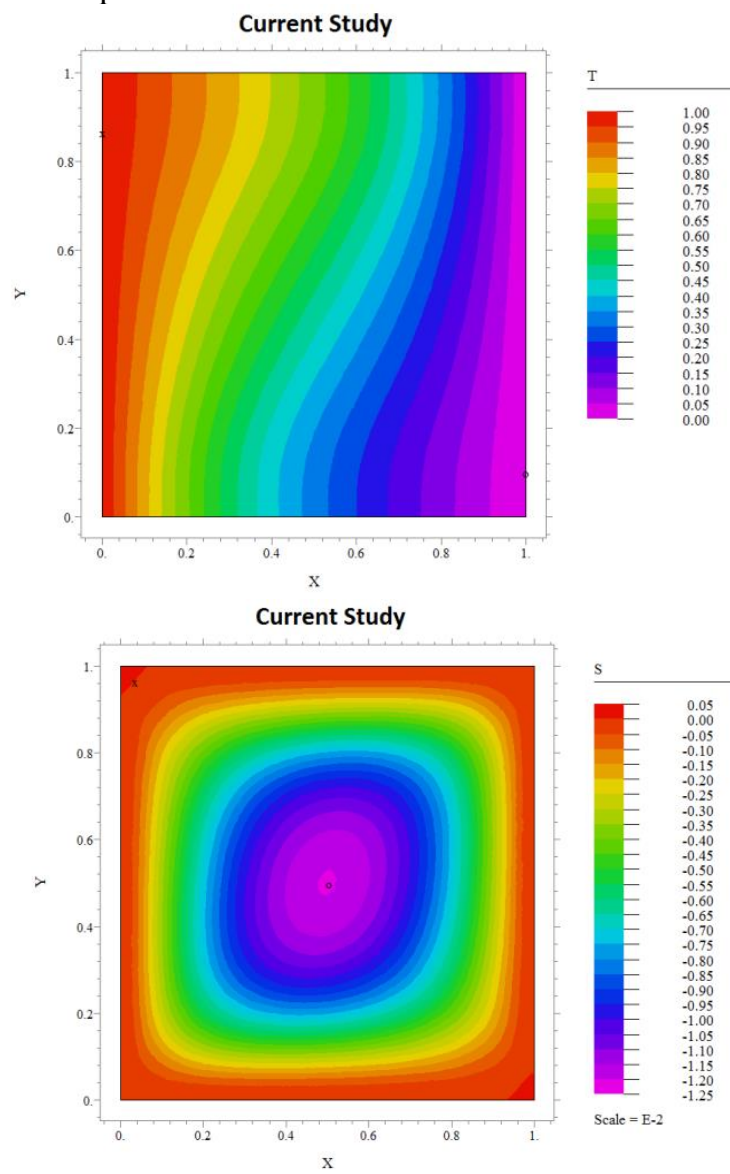

Figure 2. Validation results

To solve the dimensionless governing equations numerically, the finite element method (fem) is employed

$$
\begin{aligned}
& S_{F}=\frac{\mu_{n f} T_{0}}{k_{f}}\left(\frac{\alpha_{f}}{L \Delta T}\right)^{2} R a\left[2\left(\frac{\partial U}{\partial X}\right)^{2}+2\left(\frac{\partial V}{\partial Y}\right)^{2}+\left(\frac{\partial V}{\partial Y}+\frac{\partial U}{\partial X}\right)^{2}\right] \\
& S_{T}=\frac{k_{n f}}{k_{f}}\left[\left(\frac{\partial T}{\partial X}\right)^{2}+\left(\frac{\partial T}{\partial Y}\right)^{2}\right] \\
& S_{G}=\frac{\sigma_{n f}}{\sigma_{f}} \frac{T_{0} \mu_{f}}{k_{f}}\left(\frac{\alpha_{f}}{L \Delta T}\right)^{2} \operatorname{RaHa}^{2}(U \sin \gamma-V \cos \gamma)^{2}
\end{aligned}
$$

The total dimensionless entropy generations and the average Bejan number are obtained by numerical integration of the local dimensionless entropy generation over the entire cavity volume. It is given by:

$$
B e_{\text {ave }}=\int_{0}^{1} \int_{0}^{1} B e d x d y
$$

The local and the average Nusselt numbers at the wavy wall with the utilization of the dimensionless parameters are [15]

$$
\begin{aligned}
& N u_{l o c}=\left(-\frac{\partial T}{\partial X}\right)_{X=0} \\
& N u_{\text {ave }}=\frac{1}{L} \int_{0}^{L} N u_{l o x} d Y
\end{aligned}
$$

And the average Nusselt number on surfaces

\section{NUMERICAL METHOD AND VALIDATION}
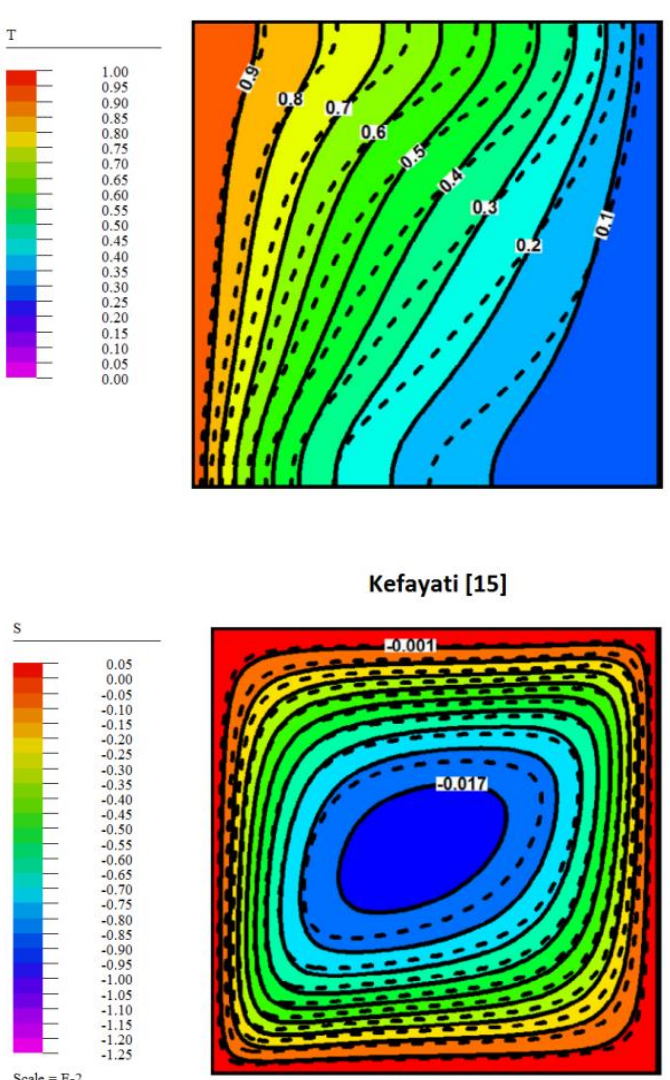
4. to validate the independence of the grids, the num of the wavy wall is considered as the criterion; and three different geometries of wavy walls with amplitude of am $=0.1,0.2$ and 0.3 are considered. Fig. 1 indicates the geometry, boundary conditions and generated mesh. To validate the nanofluid in free convection condition, a comparison is performed among the present study results and reference [15] in fig. 2 where a good agreement is observed with the results stated in kefayati [15].

\section{DISCUSSION AND RESULTS}

As explained in introduction section, this study aims to investigate the natural convection in a wavy wall square cavity; the cavity is filled with $\mathrm{Fe}_{3} \mathrm{O}_{4}$-non-Newtonian Nanofluid; and the goal is to find its best heat transfer performance with the least possible amount of entropy generation. Table 1 indicates the thermo-physical properties of $\mathrm{Fe}_{3} \mathrm{O}_{4}$ Nanoparticles properties.

The following dimensionless parameters are considered in this study:

- Nanoparticles volume fraction $(\varphi)$ : changes from $2 \%$ to $6 \%$.

- Hartmann number (Ha): changes between 20 to100.

- $\quad$ Angle of magnetic field $(\gamma)$ : varies from 0 to 60.

- The amplitude of the wavy wall (Am): varies from 0.1 to 0.3 .

- The nanoparticles shape: platelet, cylindrical, spherical and brick shapes

Fig. 3 indicates the streamline and isotherm contours in the three different geometry of the cavity. The contours have been traced for the Rayleigh number of $10000, \mathrm{Ha}=20, \mathrm{n}=1, \gamma=0$, and spherical Nanoparticles with $\varphi=2 \%$. As seen, in all temperature contours the left wavy side is cooler and right wall is in hot temperatures due to boundary conditions. By increasing the Am, peak of the wavy shape will be near to center of the cavity or more near to hot wall, it causes a separation in the natural flow pattern in the streamline while for $A m=0.3$ the separation of stream lines completely occurred to two different areas. Also, in temperature contours it causes colder temperatures in the center cavity due to cold temperature of the wavy wall. Fig. 4 shows the effect of this parameter on the details of entropy generation components, i.e.: entropy generations due to fluid flow (SF), the magnetic field (SG) and heat transfer (ST). Because the main mechanism in this problem is heat transfer (due to natural convection), the entropy generations due to heat transfer (ST) has more changes while entropy of fluid flow (SF) is the least. The entropy generation is also a function of shape of cavity due to different in irreversibility of heat transfer for each geometry. To have a good comparison, Figs. 5 are depicted and confirm that increasing in Am, makes a significant increment in the all entropy generation components. Also, it improved the Nusselt and Bejan numbers which says better heat transfer and more ST, respectively.

To show the effect of the magnetic field angle applied to the geometry Fig. 6 and 7 are depicted for the temperature/streamline and entropy generation components, respectively. It is observed when the magnetic angle is not zero; the streamline cavity also has a slope in relation to the magnetic angle due to effect on nanoparticles (which are magnetism). Also, the most difference in entropy generation components occurred for SG which shaped in the form of applied angle to the magnetic field. Fig. 8 says that increasing the $\gamma$ averagely increases the entropy generation and Nusselt number, while it decreased the Bejan number, averagely. Decreasing the Bejan number means that ST growth is smaller than total entropy generation rate. Another parameter of magnetic field effect is Hartmann number ( $\mathrm{Ha}$ ) which its effect on the results is presented via Fig. 9 and 10. Increasing in Hartmann makes a separation on the streamline and two centers of created vortexes have more tendencies to be near to walls due to nanoparticles motions in this situation. Fig. 11 confirms that increasing in the $\mathrm{Ha}$, make a reduction in average Nusselt number and increase in Bejan numbers due to increment in irreversibility of heat transfer.

Effects of nanoparticles volume fraction on the results are depicted in Fig. 12, 13 and 14. When the nanoparticle volume fraction increases, the generated entropy will decrease due to more dense fluid. Furthermore, increasing the $\varphi$, caused an increase on the Nusselt number due to more heat transfer mechanism by larger nanoparticles volume fraction and it will increase the ST which leads to increase in Bejan number by refer to its definition.

Finally, the effect of four nanoparticles shapes (platelet, cylindrical, spherical and brick shapes) on the outcomes are presented in Figs. 15, 16 and 17. It is found that brick-shaped nanoparticles generate the most entropy while the cylindrical one has the least. Furthermore, this shape of nanoparticle has the maximum average Nusselt number and minimum Bejan number, while spherical shape of nanoparticles has the minimum $\mathrm{Nu}$ and maximum $\mathrm{Be}$ number among the other nanoparticles.
Temp.

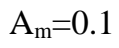

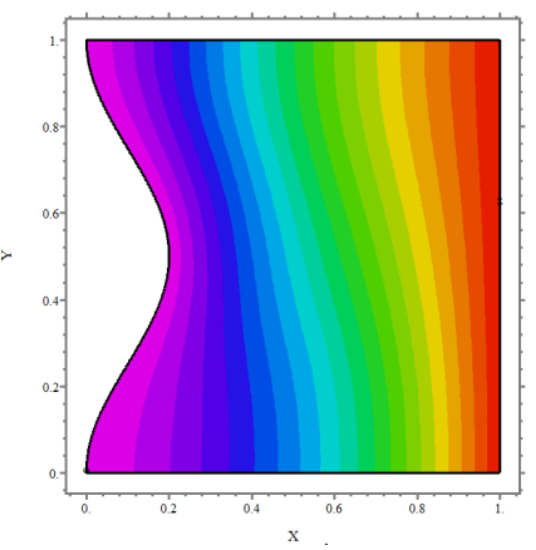

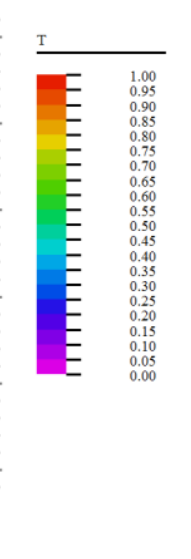

Stream Line

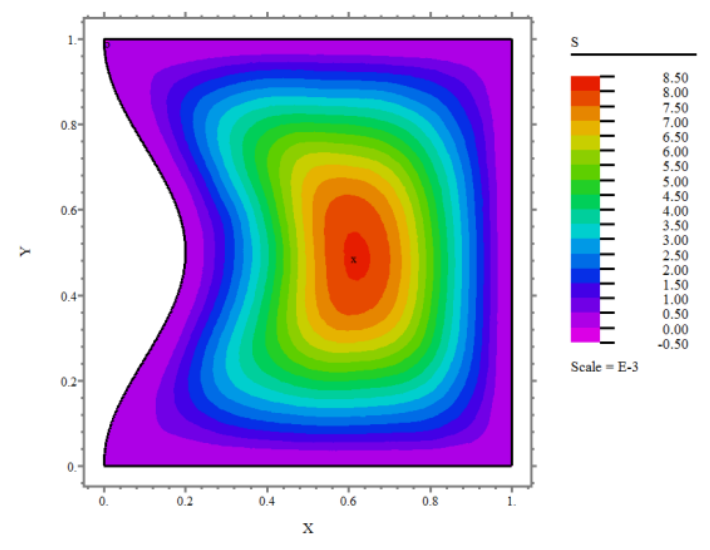


$\mathrm{A}_{\mathrm{m}}=0.2$
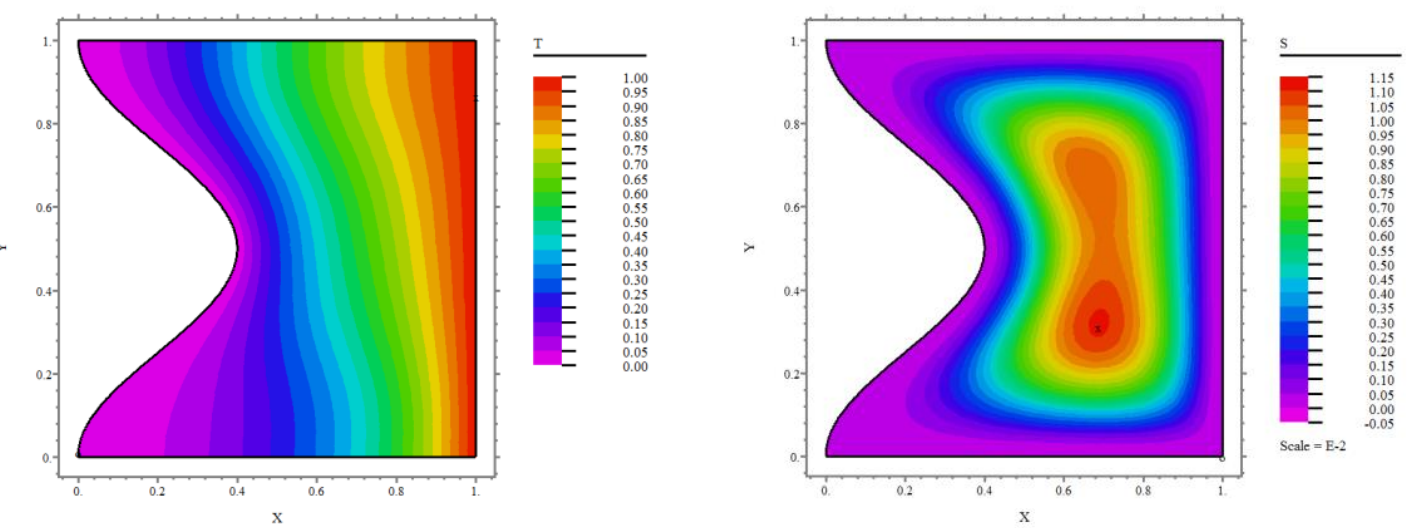

$\mathrm{A}_{\mathrm{m}}=0.3$
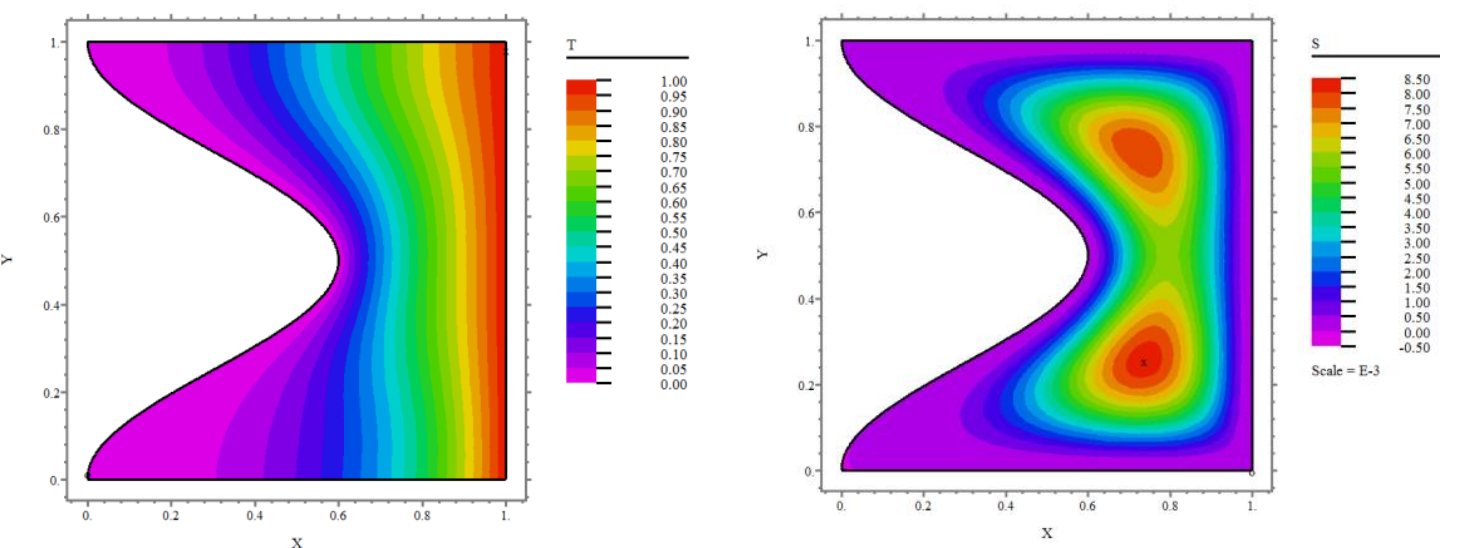

Figure 3. Effect of $A_{m}$ on temperature and streamlines

$\mathrm{S}_{\mathrm{T}}$
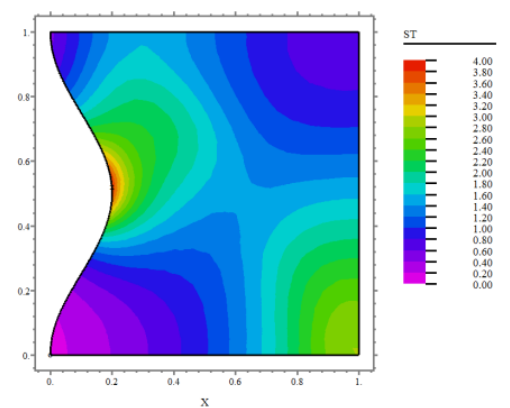

$\mathrm{S}_{\mathrm{F}}$
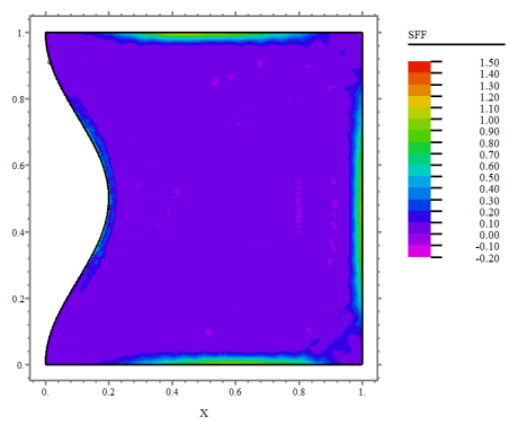

$\mathrm{S}_{\mathrm{G}}$

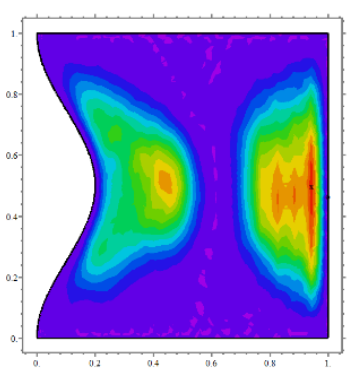

$\mathrm{A}_{\mathrm{m}}=0.2$
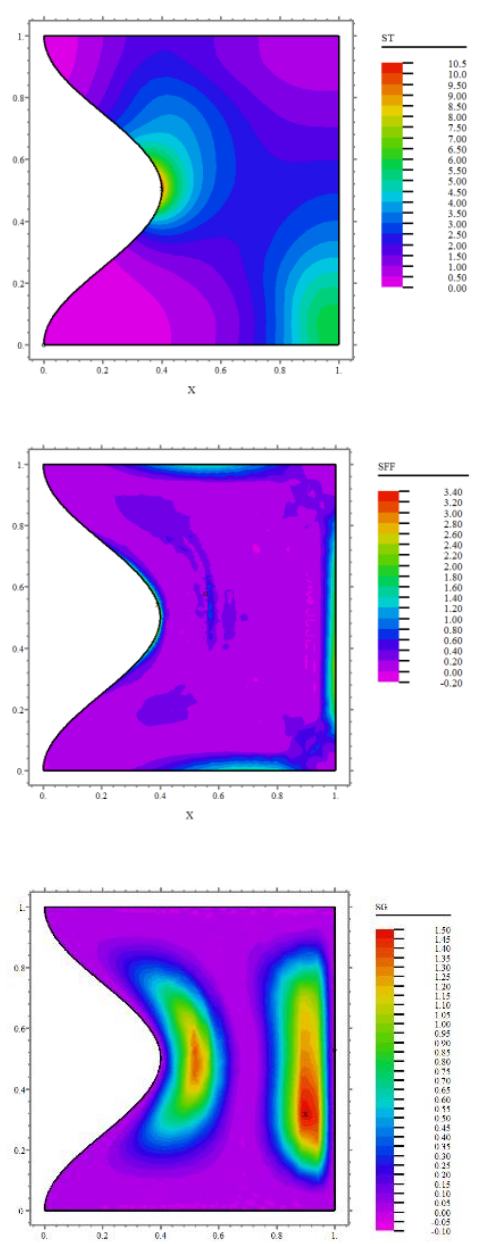

$\mathrm{A}_{\mathrm{m}}=0.3$
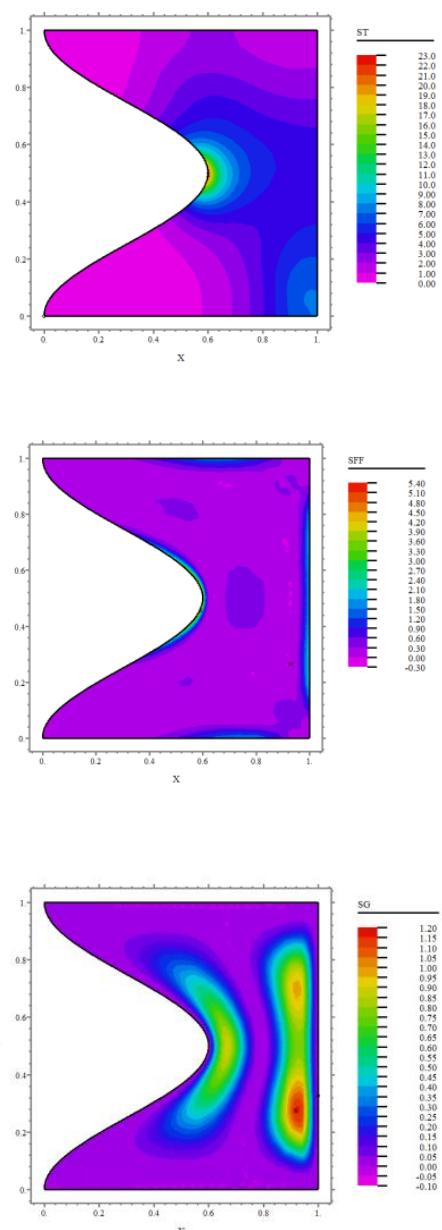

Figure 4. Effect of $A_{m}$ on entropy generation terms 

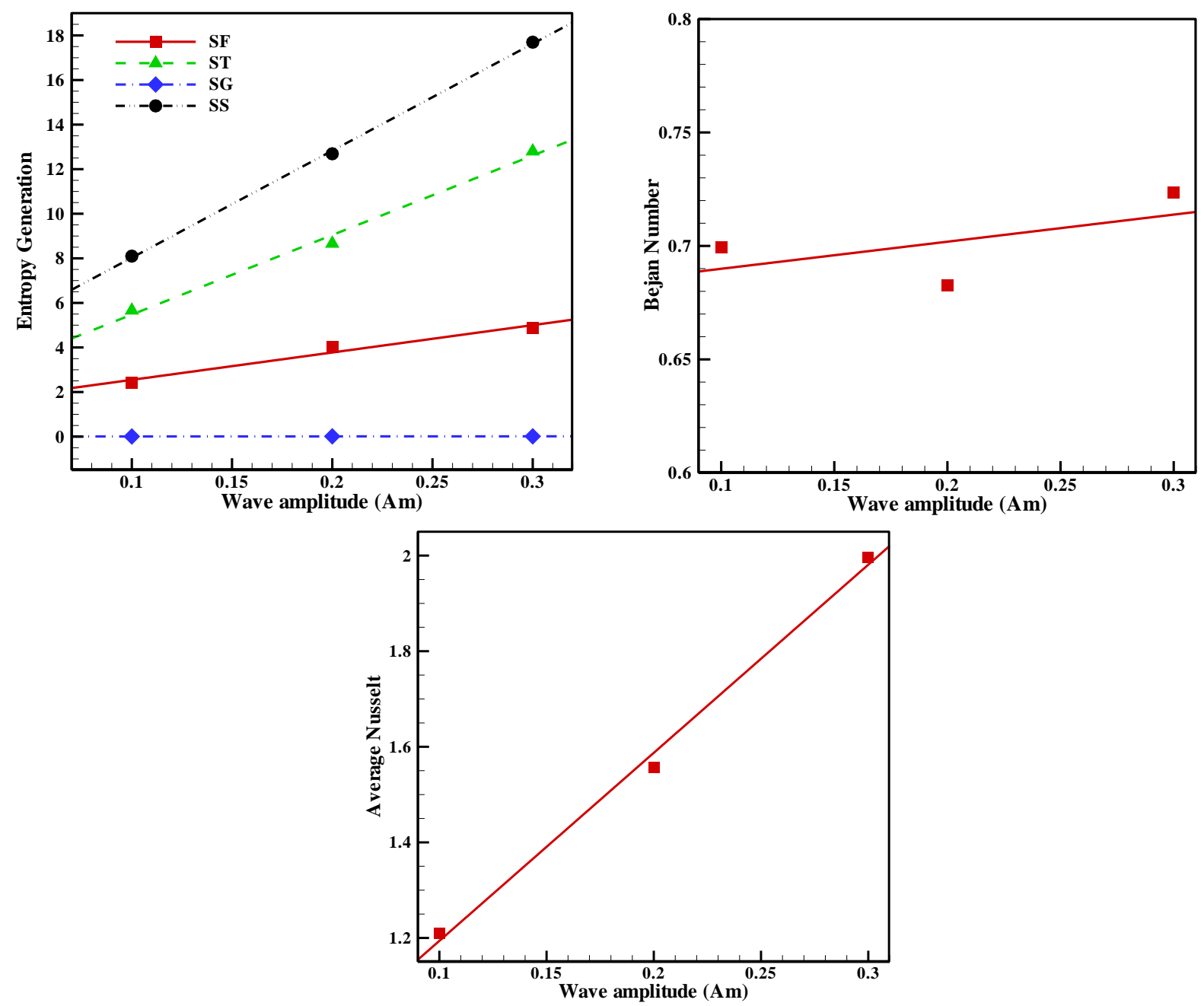

Figure 5. Entropy generation parameters, Bejan and Nusselt numbers in different $A_{m}$

$\gamma=0$

Temp.

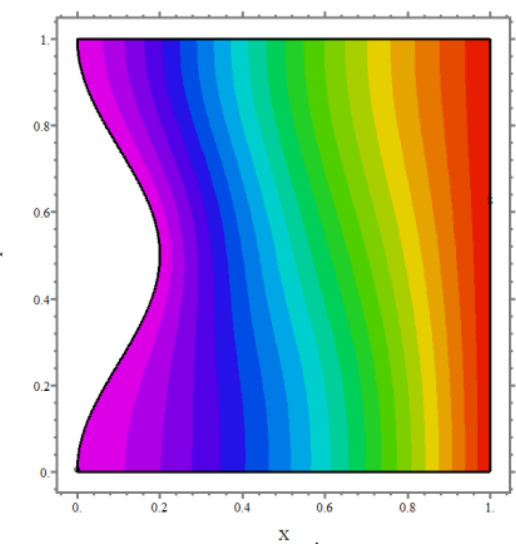

$\gamma=30$

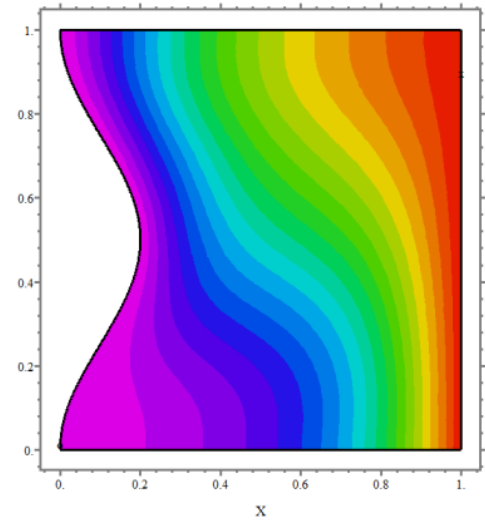

Stream Line
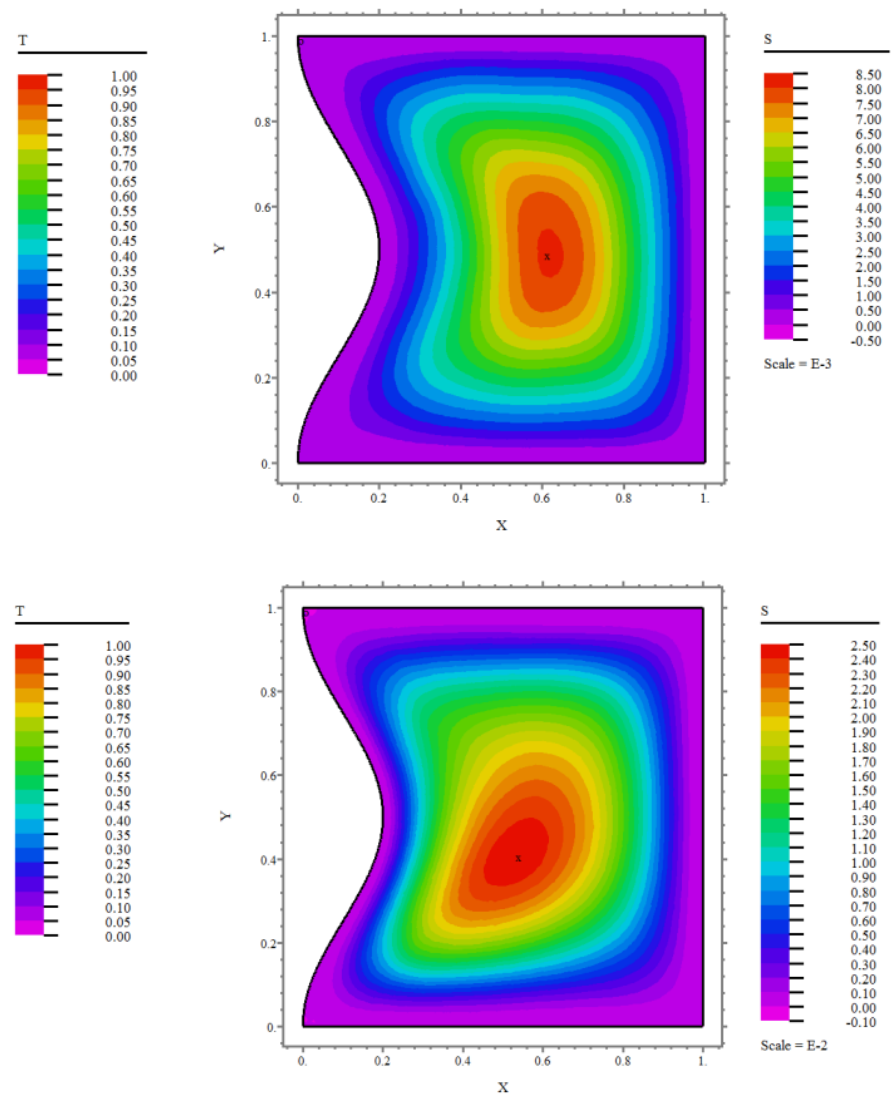
$\gamma=60$
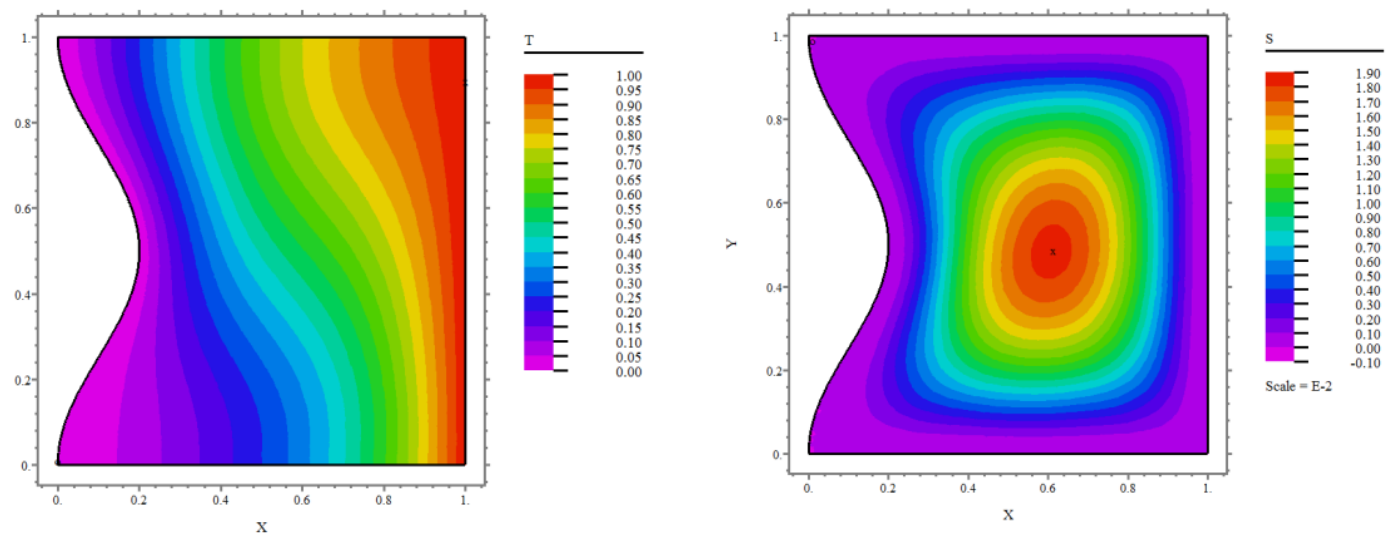

$\mathrm{S}_{\mathrm{T}}$

$\gamma=0.0$
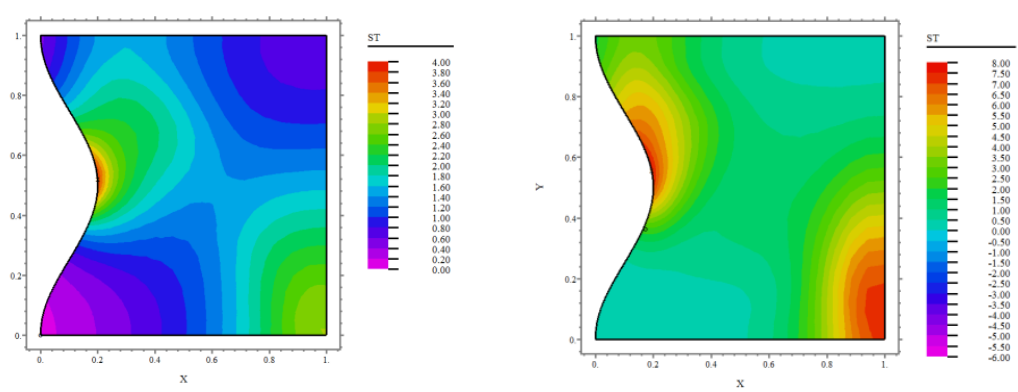

$\gamma=60$

$\mathrm{S}_{\mathrm{F}}$
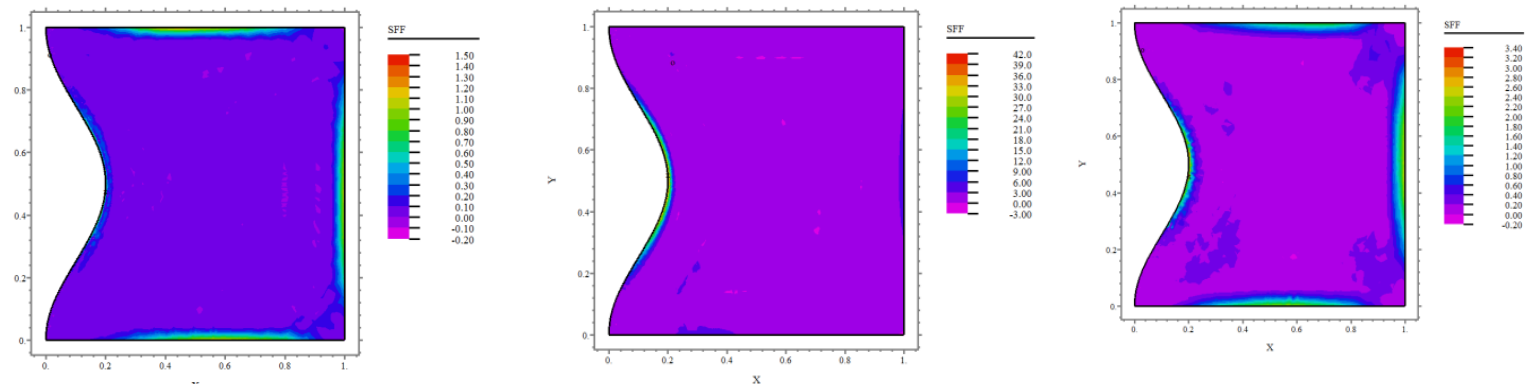

$\mathrm{S}_{\mathrm{G}}$
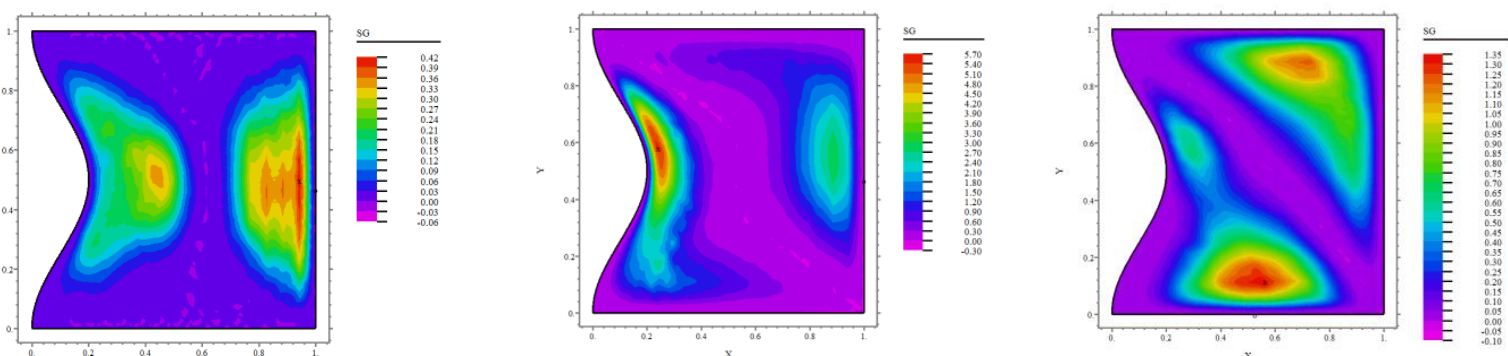

Figure 7. Effect of $\gamma$ on entropy generation terms
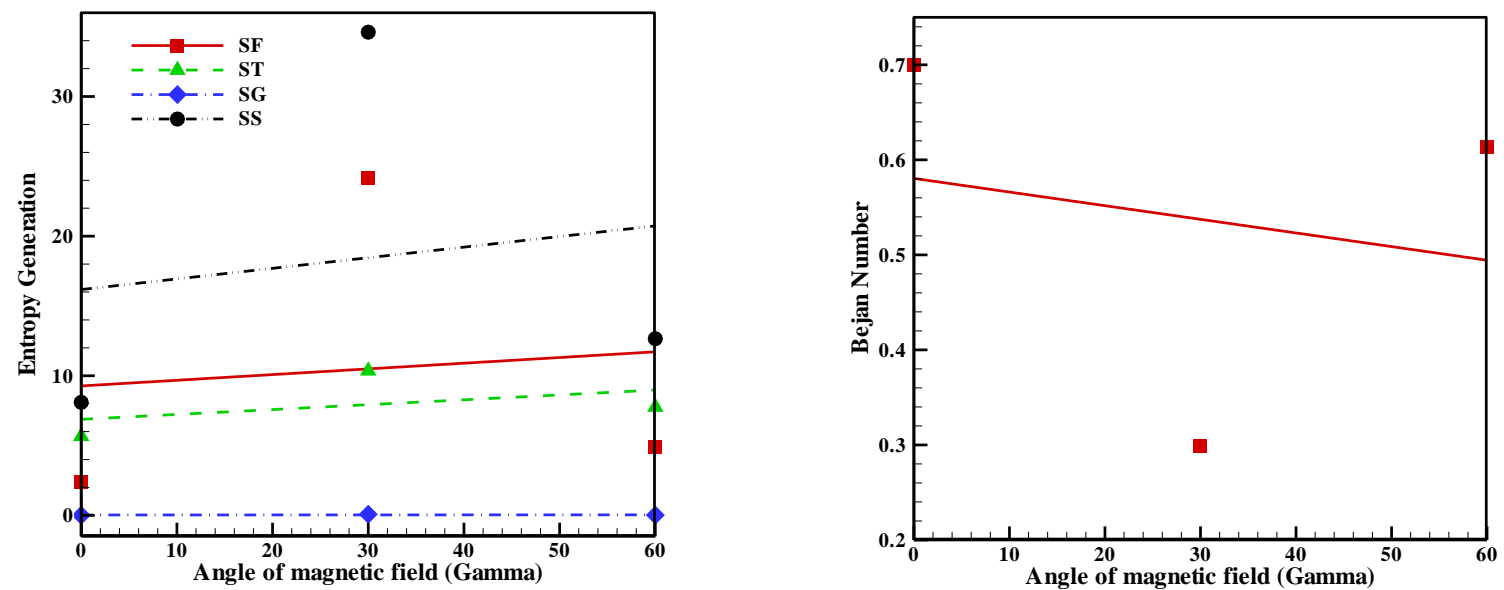


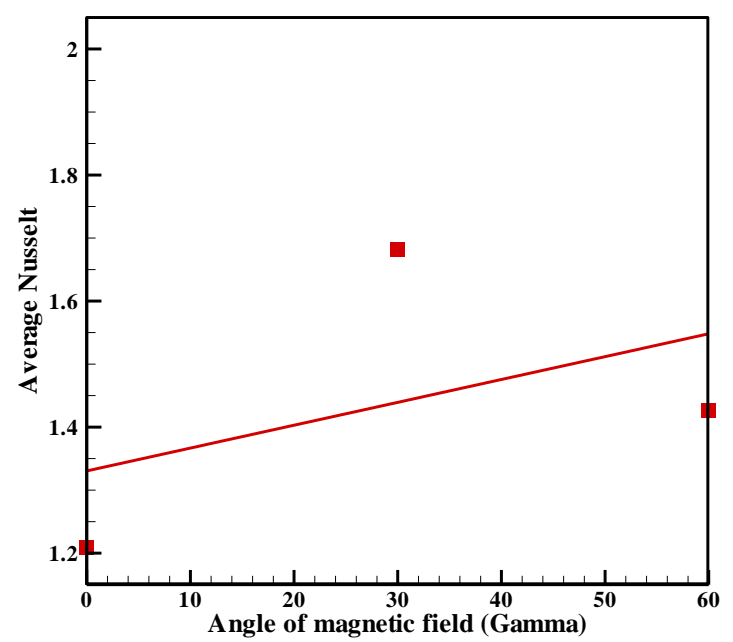

Figure 8. Entropy generation parameters, Bejan and Nusselt numbers in different $\gamma$

$\mathrm{Ha}=20$
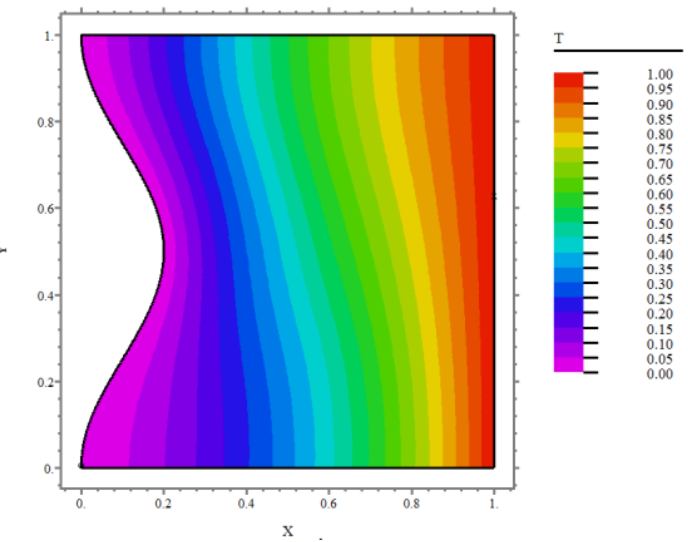

$\mathrm{Ha}=60$
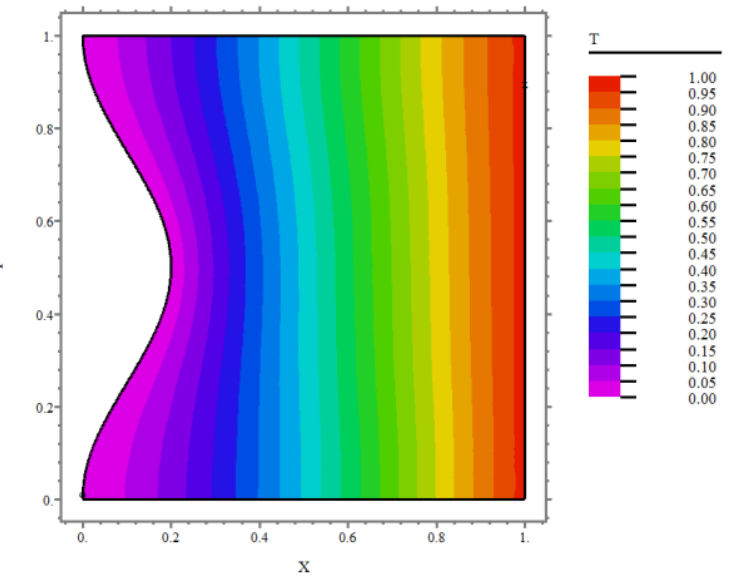

Stream Line
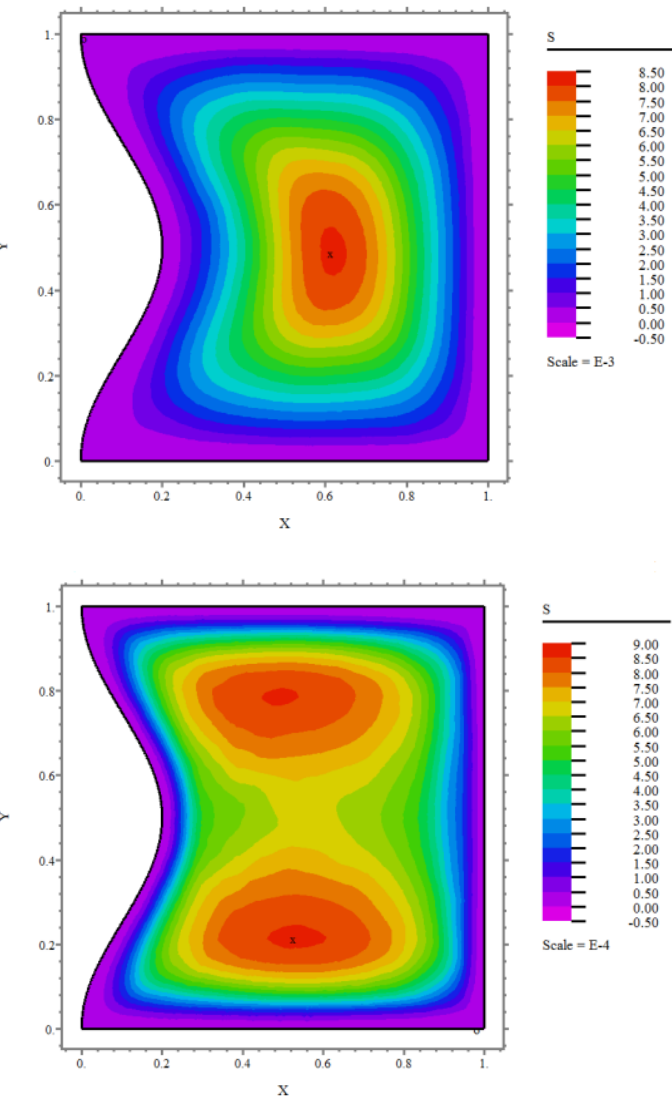

$\mathrm{Ha}=100$
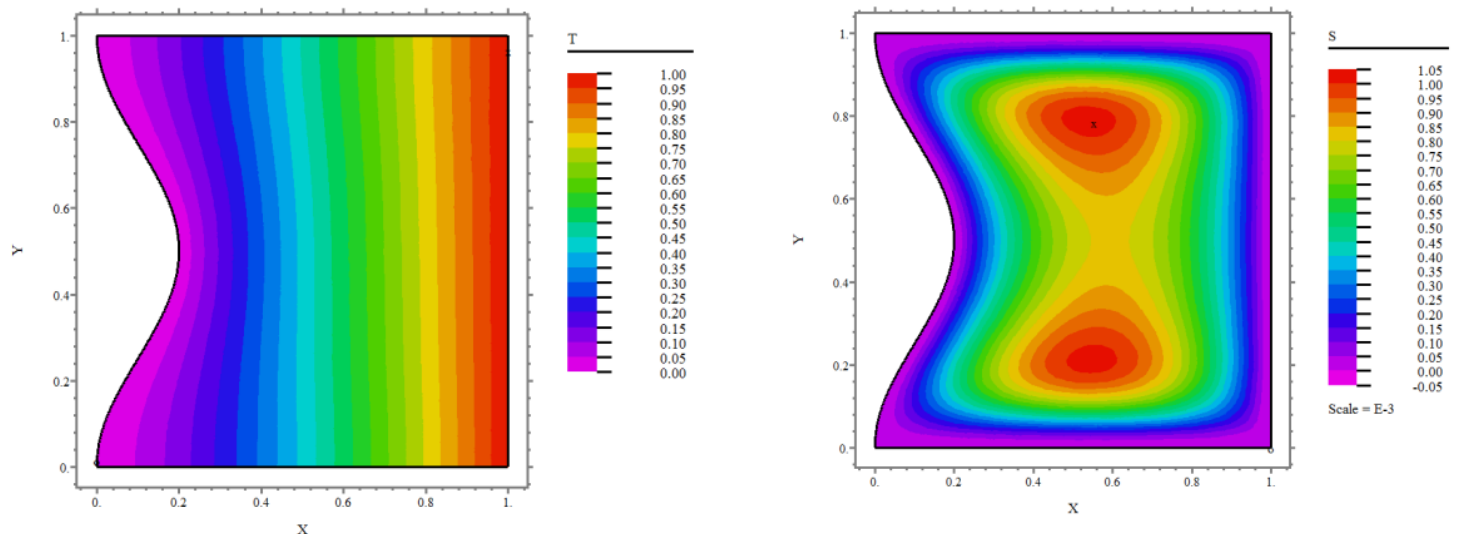

Figure 9. Effect of Ha on temperature and streamlines 
$\mathrm{Ha}=20$

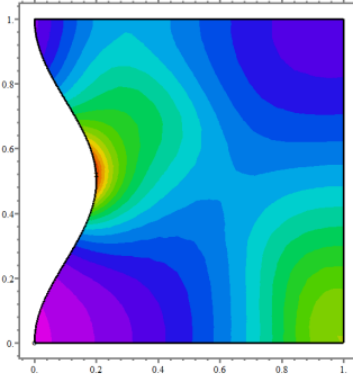

$\mathrm{S}_{\mathrm{T}}$
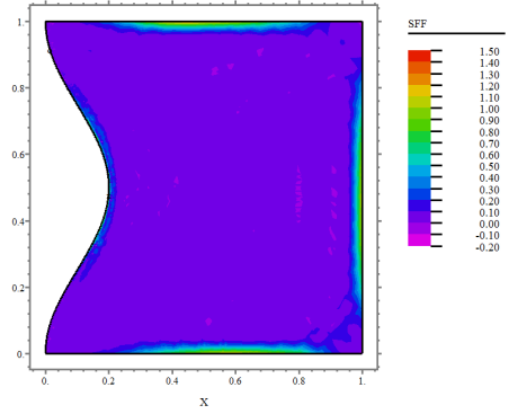

$\mathrm{S}_{\mathrm{F}}$
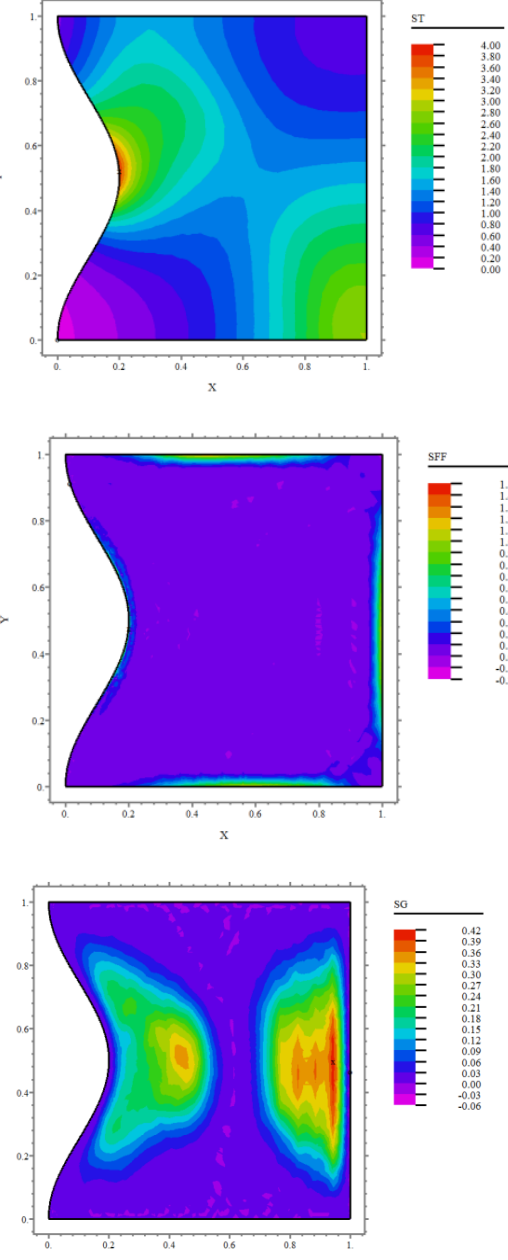

$\mathrm{Ha}=100$
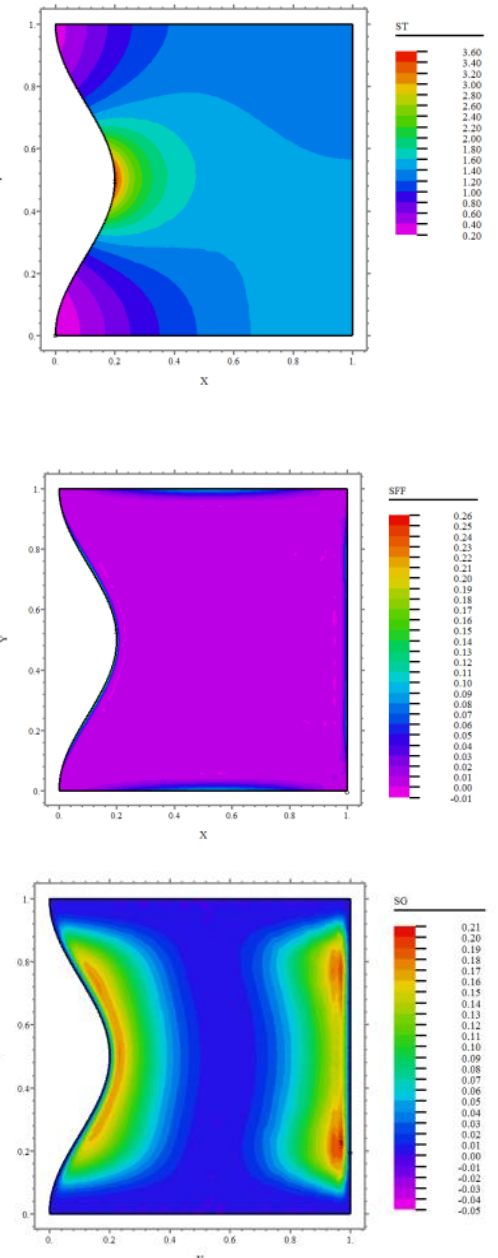

$\mathrm{S}_{\mathrm{G}}$

Figure 10. Effect of Ha on entropy generation terms
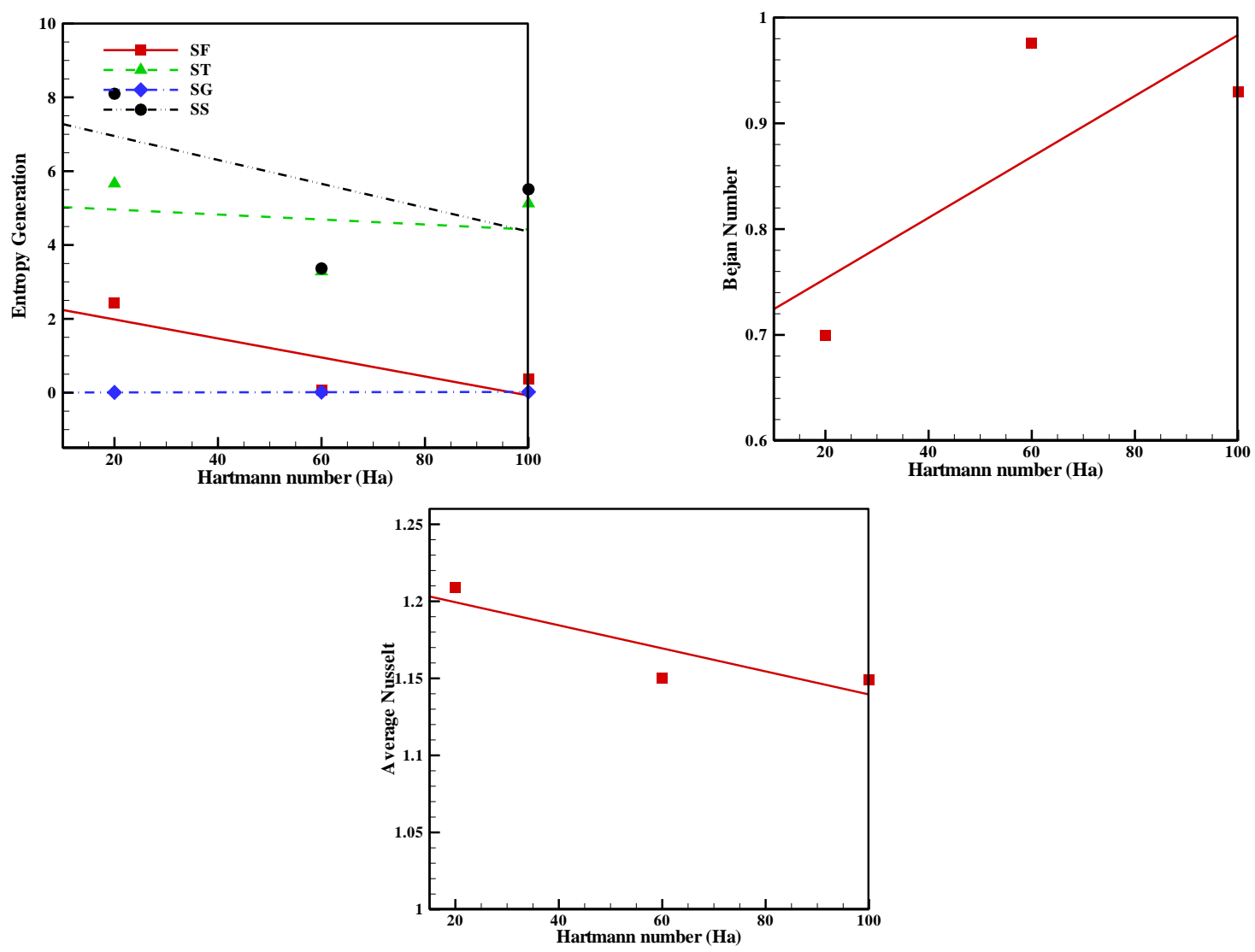

Figure 11. Entropy generation parameters, Bejan and Nusselt numbers in different Ha numbers 


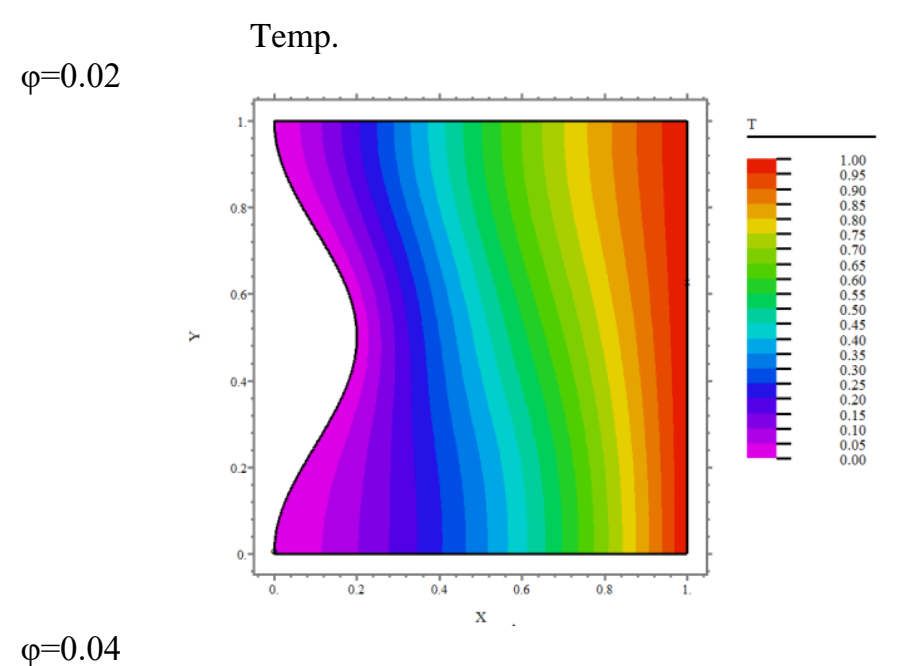

Stream Line

$\varphi=0.04$
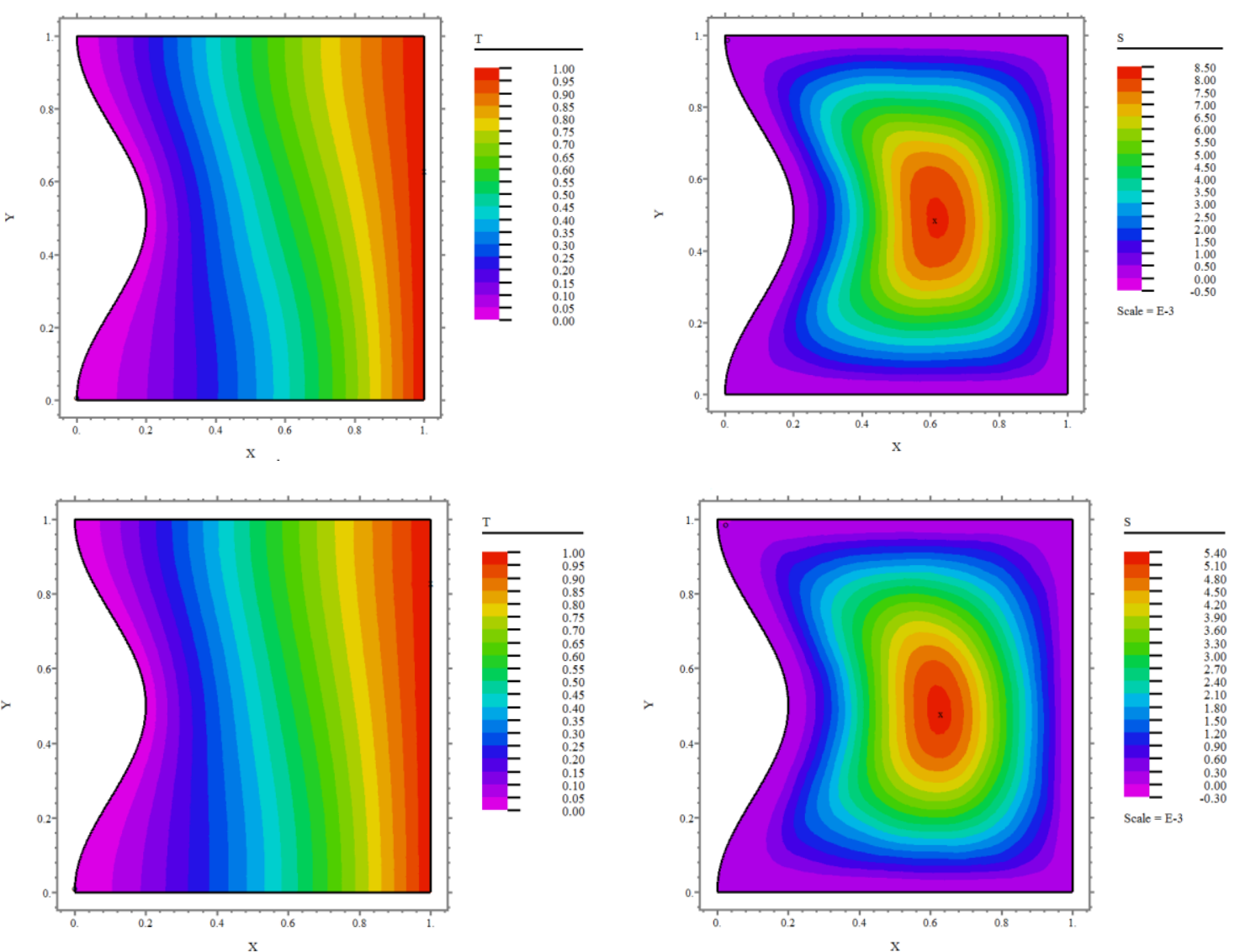

Figure 12. Effect of phi on temperature and streamlines

$\mathrm{S}_{\mathrm{T}}$

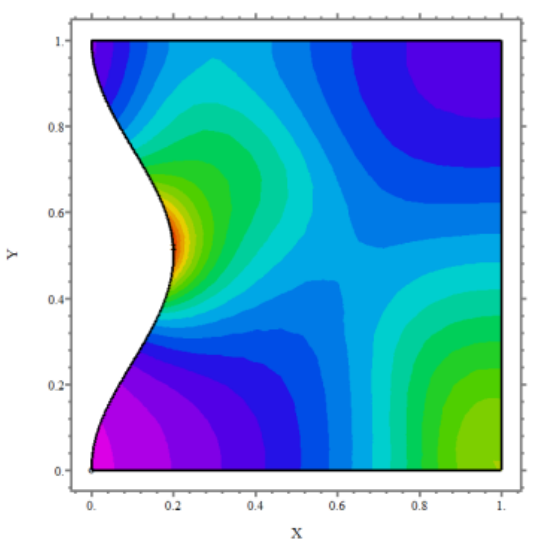

$\mathrm{S}_{\mathrm{F}}$

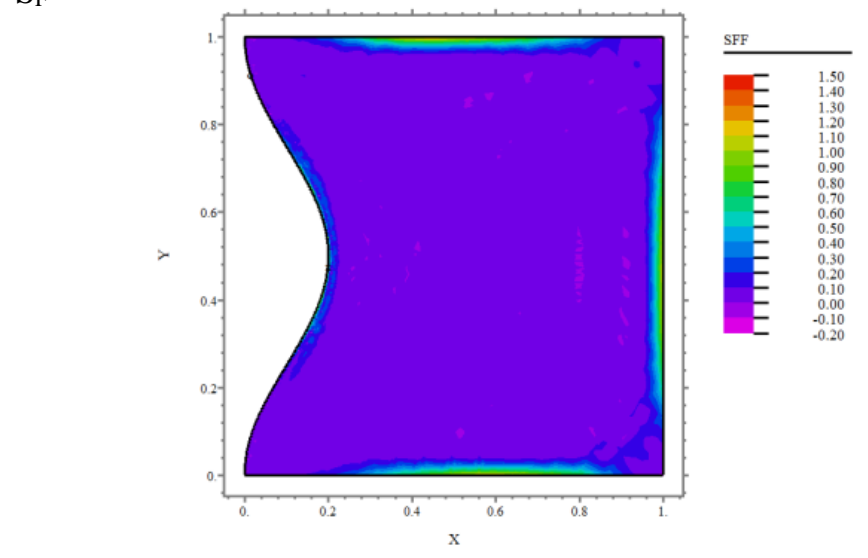

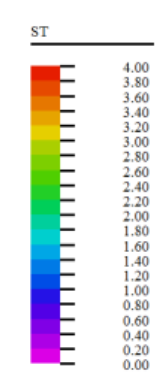
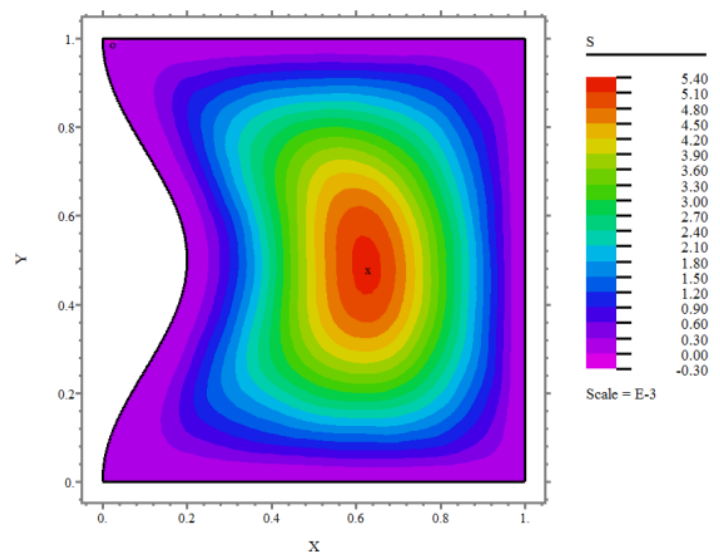

$\Phi=0.04$
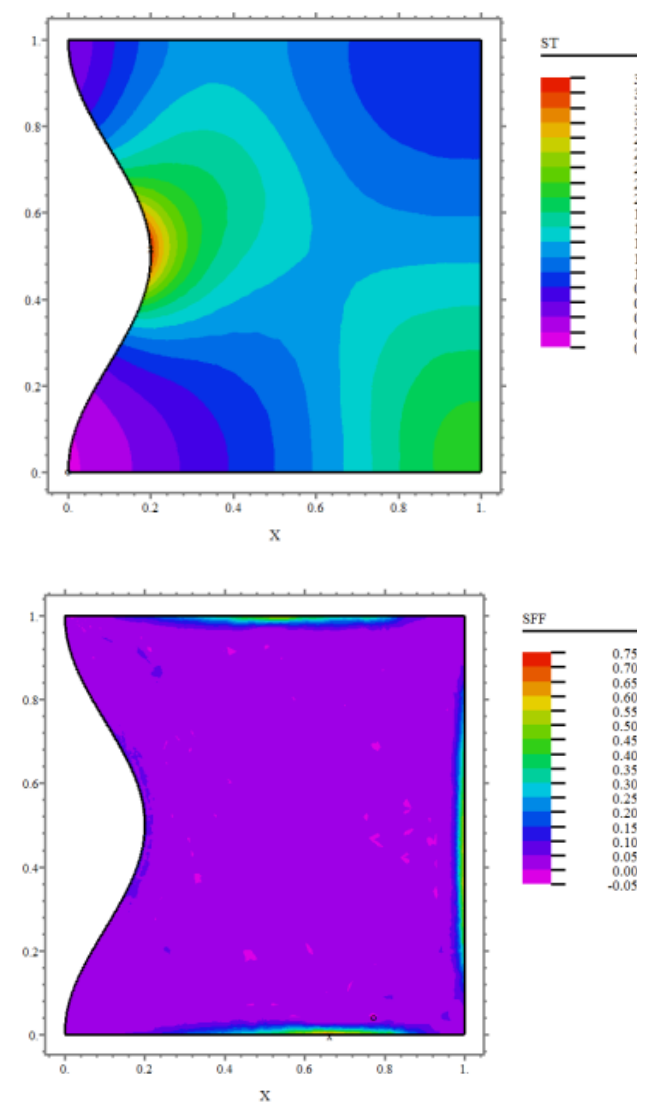
$\mathrm{S}_{\mathrm{G}}$
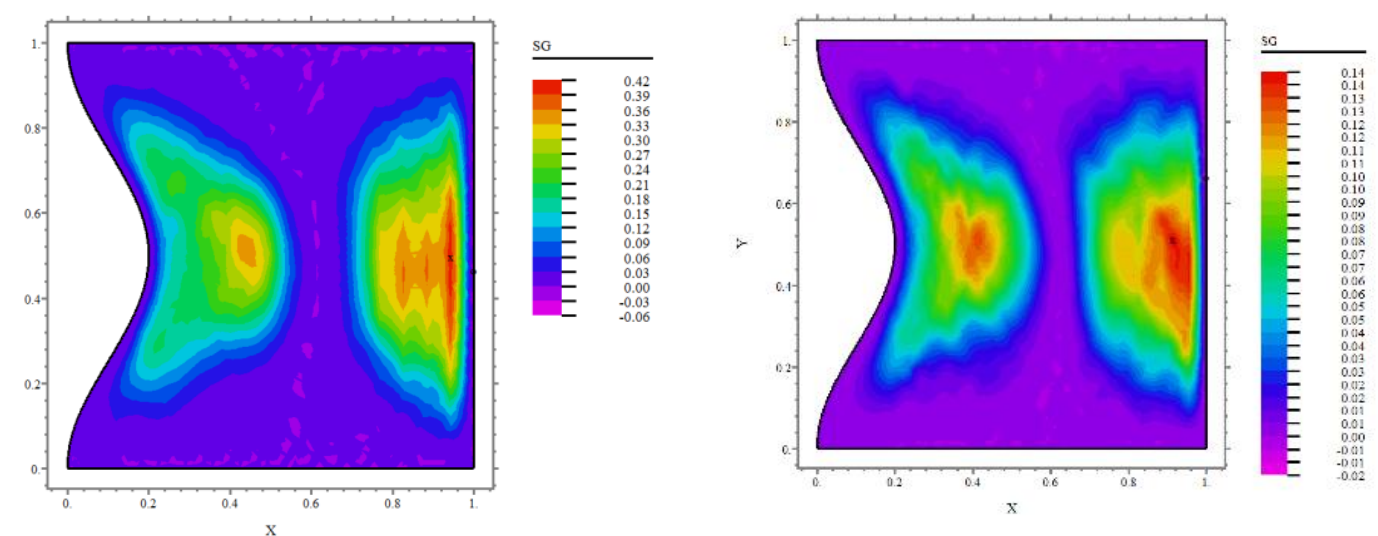

Figure 13. Effect of phi on entropy generation terms
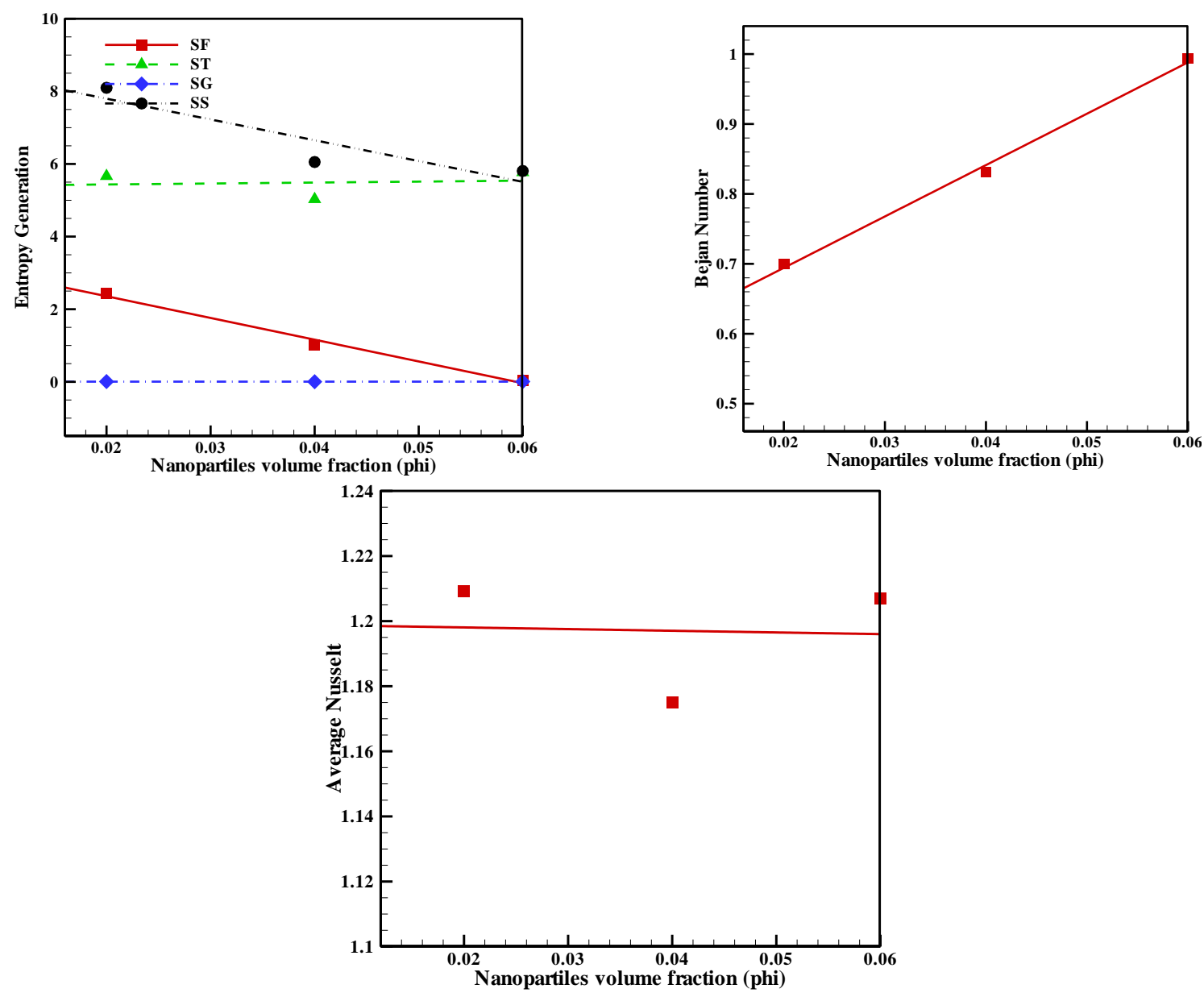

Figure 14. Entropy generation parameters, Bejan and Nusselt numbers in different $\varphi$

\section{Platelet}

Temp.

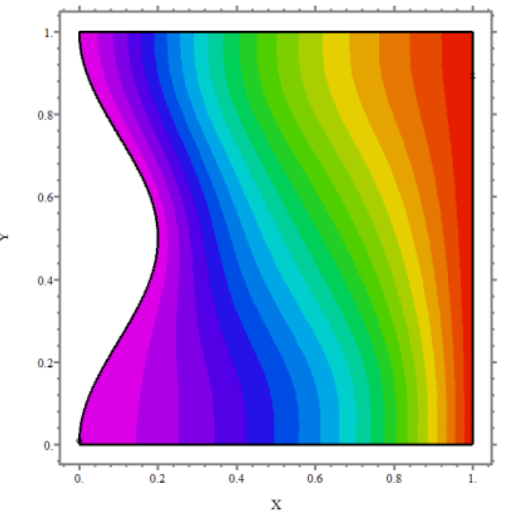

Stream Line

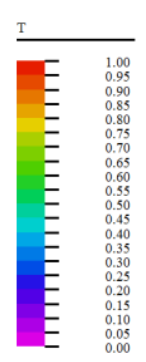

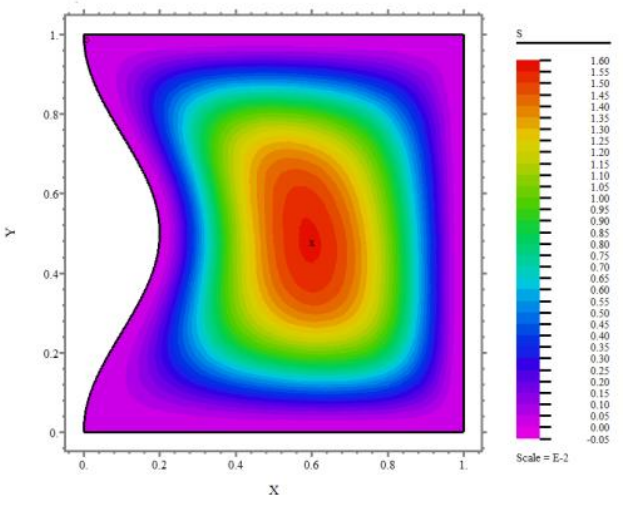


Brick
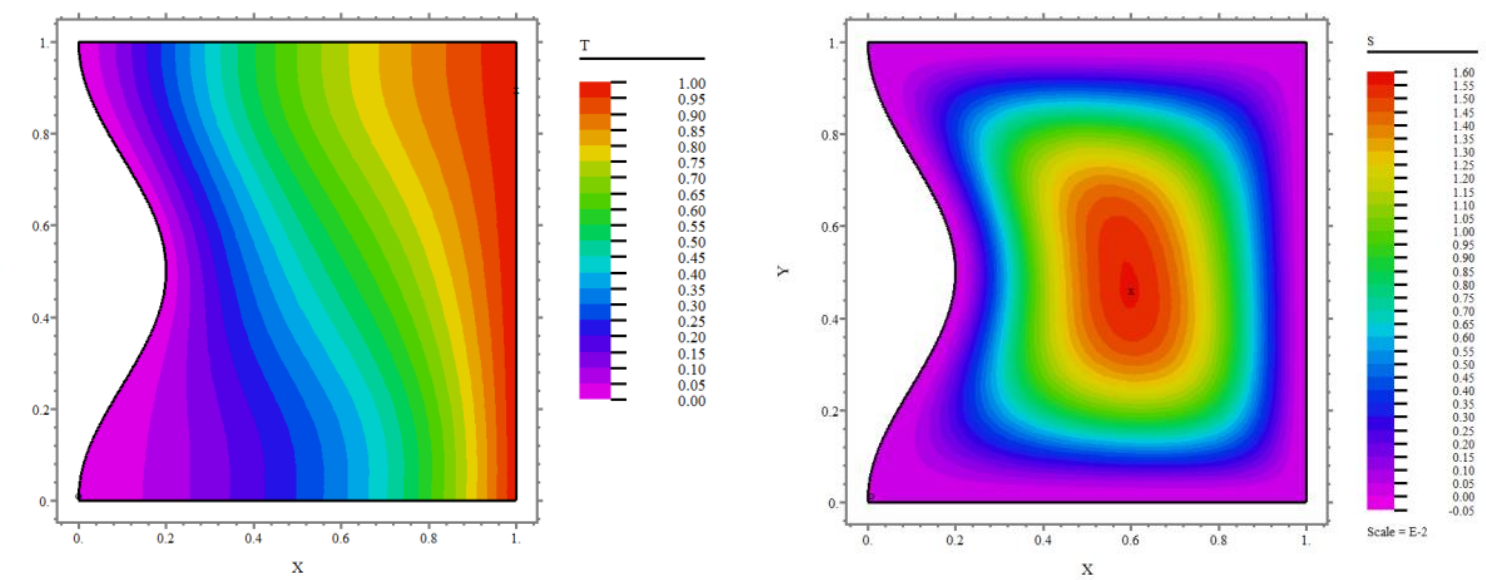

Spherical
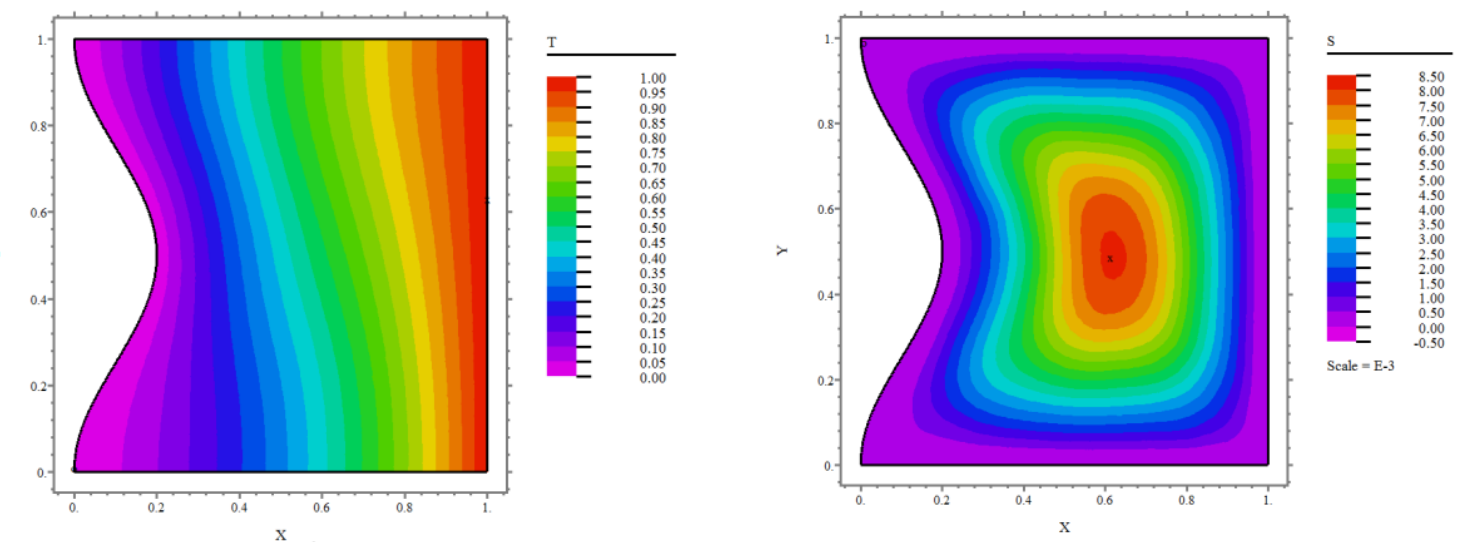

Figure 15. Effect of $\psi$ on temperature and streamlines

Platelet
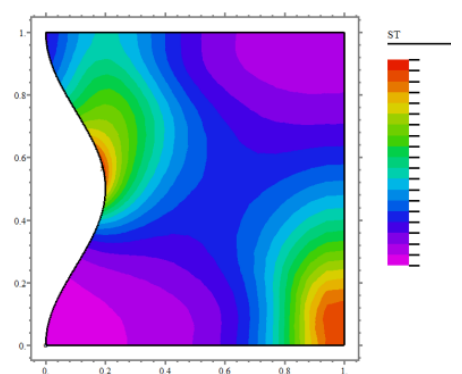

Brick
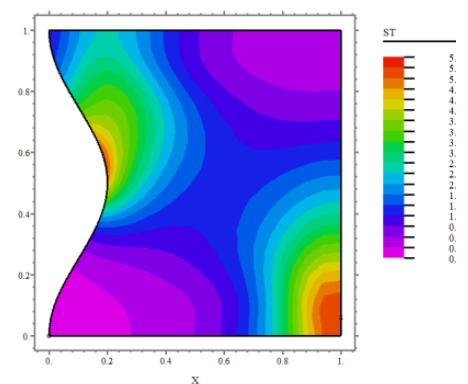

Spherical

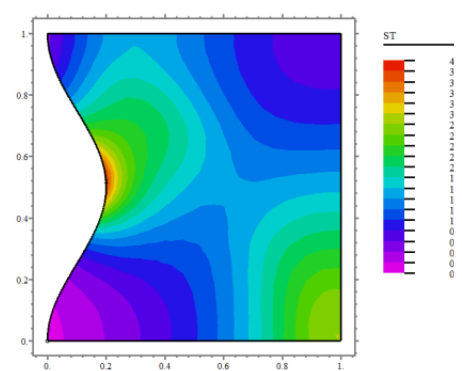

$\mathrm{S}_{\mathrm{F}}$
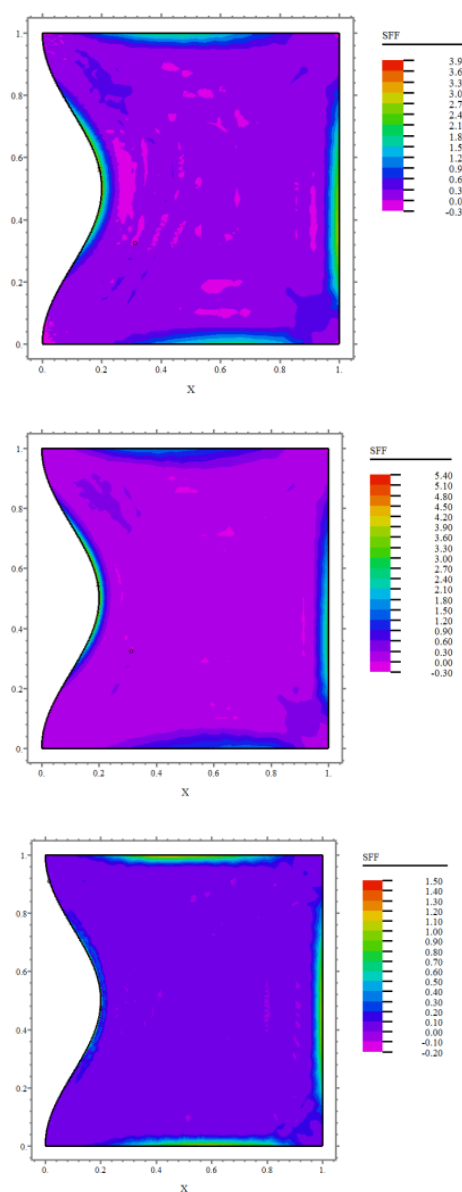

$\mathrm{S}_{\mathrm{G}}$
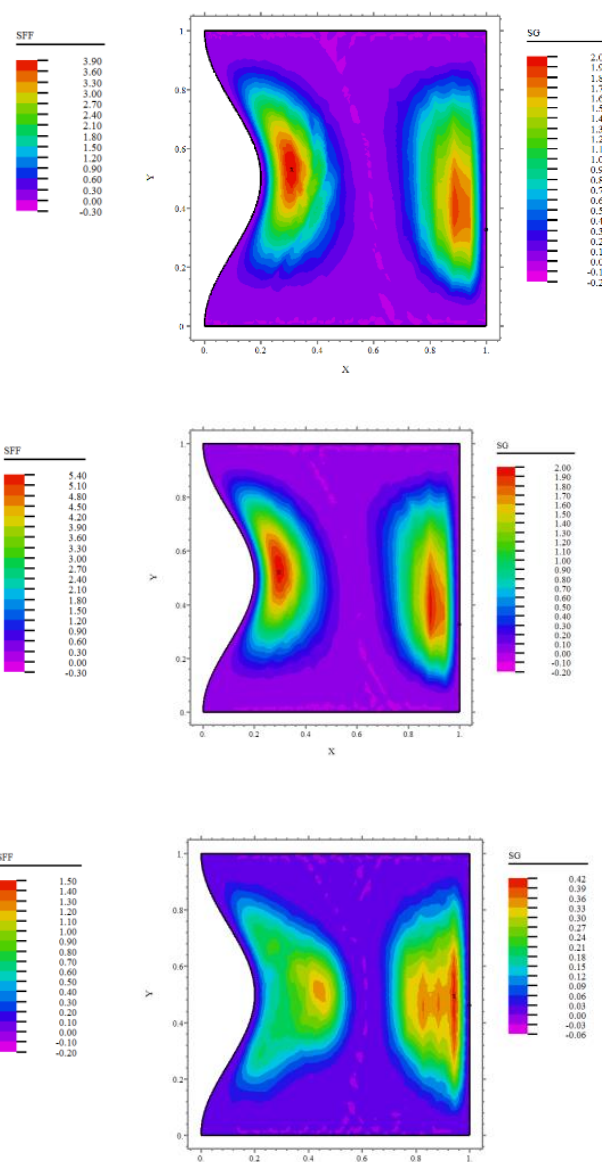

Figure 16. Effect of $\psi$ on entropy generation terms 

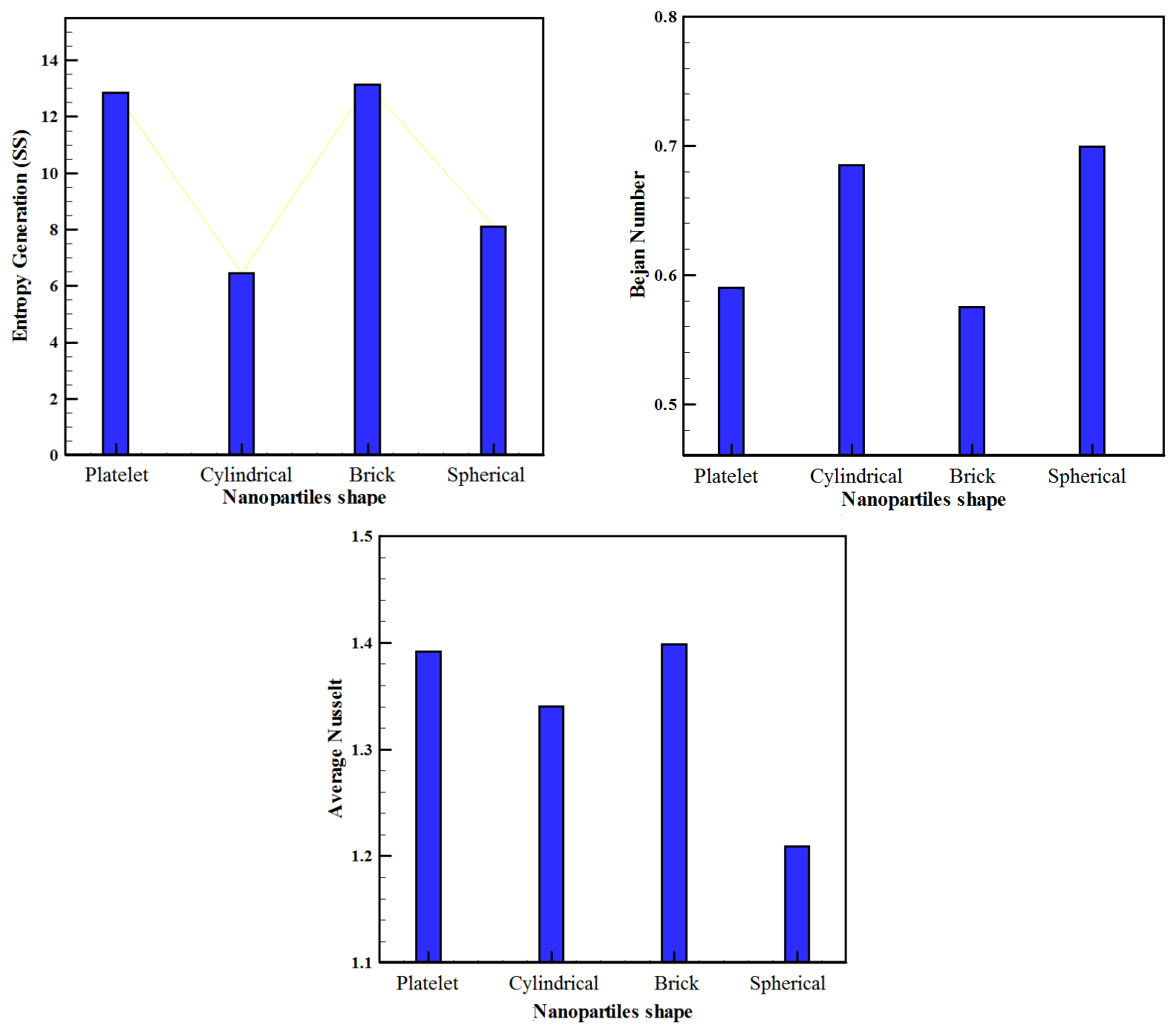

Figure 17. Entropy generation parameters, Bejan and Nusselt numbers in different nanoparticle shapes

\section{CONCLUSIONS}

In present investigation, natural convection in a Nanofluid filled square wavy-walled cavity was studied numerically. In this simulation, the impacts of the Nanoparticles shape and volume fraction, the wavy surface amplitude, Hartmann number and magnetic angle on the entropy generation and the mean Nusselt and Bejan numbers are studied. The results obtained are summarized as follows:

- The average Nusselt number enhances with the wave amplitude (Am). Additionally, Am improved the Nusselt and Bejan numbers which says better heat transfer and more ST, respectively.

- The highest average Nusselt number is observed for the Nanofluid with brick shaped particles; however, the Nanofluid with spherical shaped particles is found to have the lowest $\mathrm{Nu}$.

- Increasing the angle of magnetic field $(\gamma)$ averagely increases the entropy generation and Nusselt number, while it decreased the Bejan number.

- Increasing the Hartmann number, make a reduction in average Nusselt number and increase in Bejan number due to increment in irreversibility of heat transfer.

- Minimum and maximum Bejan numbers were observed for brick and spherical nanoparticles, respectively.

\section{ACKNOWLEDGMENT}

Author gratefully acknowledges the Education and Research Office of Esfarayen University of Technology (EUT) for the financial support of this project as a research plan in that university.

\section{REFERENCES}

[1] Behzadi T, Milani Shirvan K, Mirzakhanlari S, Alaie Sheikhrobat A. (2015). Numerical simulation on effect of porous medium on mixed convection heat transfer in a ventilated square cavity. Procedia Engineering 127: 221-228. https://doi.org/10.1016/j.proeng.2015.11.333

[2] Hatami M, Khazayinejad M, Jing D. (2016). Forced convection of Al2O3-water nanofluid flow over a porous plate under the variable magnetic field effect. International Journal of Heat and Mass Transfer 102: 622-630.

https://doi.org/10.1016/j.ijheatmasstransfer.2016.06.075

[3] Hayat T, Imtiaz M, Alsaedi A, Kutbi MA. (2015). MHD three-dimensional flow of nanofluid with velocity slip and nonlinear thermal radiation. Journal of Magnetism and Magnetic Materials 396: 31-37. https://doi.org/10.1016/j.jmmm.2015.07.091 
[4] Mamourian M, Milani Shirvan K, Ellahi R, Rahimi AB. (2016). Optimization of mixed convection heat transfer with entropy generation in a wavy surface square liddriven cavity by means of Taguchi approach. International Journal of Heat and Mass Transfer 102: 544-554.

https://doi.org/10.1016/j.ijheatmasstransfer.2016.06.056

[5] Hatami M, Safari H. (2016). Effect of inside heated cylinder on the natural convection heat transfer of nanofluids in a wavy-wall enclosure. International Journal of Heat and Mass Transfer 103: 1053-1057. https://doi.org/10.1016/j.ijheatmasstransfer.2016.08.029

[6] Mohyud-Din ST, Zaidi ZA, Khan A, Ahmed N. (2015). On heat and mass transfer analysis for the flow of a nanofluid between rotating parallel plates. Aerospace Science and Technology 46: 514-522. https://doi.org/10.1016/j.ast.2015.07.020

[7] Khan JA, Mustafa M, Hayat T, Alsaedi A. (2015). Threedimensional flow of nanofluid over a non-linearly stretching sheet: An application to solar energy. Int. J. Heat Mass Trans. 86: 158-164. https://doi.org/10.1016/j.ijheatmasstransfer.2015.02.078

[8] Shirvan KM, Ellahi R, Mirzakhanlari S, Mamourian M. (2016). Enhancement of heat transfer and heat exchanger effectiveness in a double pipe heat exchanger filled with porous media: Numerical simulation and sensitivity analysis of turbulent fluid flow. Applied Thermal Engineering 109: 761-774 https://doi.org/10.1016/j.applthermaleng.2016.08.116

[9] Shirvan KM, Mamourian M, Mirzakhanlari S, Ellahi R. (2016). Two phase simulation and sensitivity analysis of effective parameters on combined heat transfer and pressure drop in a solar heat exchanger filled with nanofluid by RSM. Journal of Molecular Liquids 220: 888-901. https://doi.org/10.1016/j.molliq.2016.05.031

[10] Shirvan KM, Mamourian M, Mirzakhanlari S, Ellahi R, Vafai K. (2017). Numerical investigation and sensitivity analysis of effective parameters on combined heat transfer performance in a porous solar cavity receiver by response surface methodology. International Journal of Heat and Mass Transfer 105: 811-825. https://doi.org/10.1016/j.ijheatmasstransfer.2016.10.008

[11] Fakour M, Vahabzadeh A, Ganji DD, Hatami M. (2015). Analytical study of micropolar fluid flow and heat transfer in a channel with permeable walls. Journal of Molecular Liquids 204: 198-204. https://doi.org/10.1016/j.molliq.2015.01.040.

[12] Ghasemi SE, Hatami M, Sarokolaie AK, Ganji DD. (2015). Study on blood flow containing nanoparticles through porous arteries in presence of magnetic field using analytical methods. Physica E: Low-dimensional Systems and Nanostructures 70: 146-156. https://doi.org/10.1016/j.physe.2015.03.002

[13] Rahimi-Gorji M, Pourmehran O, Hatami M, Ganji DD. (2015). Statistical optimization of microchannel heat sink (MCHS) geometry cooled by different nanofluids using RSM analysis. The European Physical Journal Plus 130:22. https://doi.org/10.1140/epjp/i2015-15022-8

[14] Mamourian M, Shirvan KM, Pop I. (2016). Sensitivity analysis for MHD effects and inclination angles on natural convection heat transfer and entropy generation of $\mathrm{Al}_{2} \mathrm{O}_{3}$-water nanofluid in square cavity by response surface methodology. International Communications in Heat and Mass Transfer, International Communications in Heat and Mass Transfer 79: 46-57. https://doi.org/10.1016/j.icheatmasstransfer.2016.10.00 1

[15] Kefayati GHR. (2016). Simulation of heat transfer and entropy generation of MHD natural convection of nonNewtonian nanofluid in an enclosure. International Journal of Heat and Mass Transfer 92: 1066-1089. https://doi.org/10.1016/j.ijheatmasstransfer.2015.09.078

[16] Sheremet MA, Pop I. (2015). Mixed convection in a liddriven square cavity filled by a nanofluid: Buongiorno's mathematical model. Applied Mathematics and Computation 266: 792-808. https://doi.org/10.1016/j.amc.2015.05.145

[17] Ghaffarpasand O. (2016). Numerical study of MHD natural convection inside a sinusoidally heated lid-driven cavity filled with $\mathrm{Fe}_{3} \mathrm{O}_{4}$-water nanofluid in the presence of Joule heating. Applied Mathematical Modelling, 40(21-22):9165-9182. https://doi.org/10.1016/j.apm.2016.05.038

[18] Hussain S, Mehmood K, Sagheer M. (2016). MHD mixed convection and entropy generation of wateralumina nanofluid flow in a double lid driven cavity with discrete heating. Journal of Magnetism and Magnetic Materials 419: 140-155. https://doi.org/10.1016/j.jmmm.2016.06.006

[19] Hussain S, Ahmad S, Mehmood K, Sagheer M. (2016). Effects of inclination angle on mixed convective nanofluid flow in a double lid-driven cavity with discrete heat sources. International Journal of Heat and Mass Transfer. https://doi.org/10.1016/j.ijheatmasstransfer.2016.10.016

[20] Ghachem K, Kolsi L, Maatki Ch, Alghamdi A, Oztop HF, Borjini MN, Aissia HB, Al-Salem Kh. (2016). Numerical simulation of three-dimensional double diffusive convection in a lid-driven cavity. International Journal of Thermal Sciences 110:241-250. https://doi.org/10.1016/j.ijthermalsci.2016.07.004

[21] Rahmati AR, Roknabadi AR, Abbaszadeh M. (2016). Numerical simulation of mixed convection heat transfer of nanofluid in a double lid-driven cavity using lattice Boltzmann method. Alexandria Engineering Journal. https://doi.org/10.1016/j.aej.2016.08.017

[22] Jmai R, Ben-Beya B, Lili T. (2016). Numerical analysis of mixed convection at various walls speed ratios in twosided lid-driven cavity partially heated and filled with nanofluid. Journal of Molecular Liquids 221: 691-713. https://doi.org/10.1016/j.molliq.2016.05.076

[23] Kareem AKh, Mohammed HA, Hussein AK, Gao Sh. (2016). Numerical investigation of mixed convection heat transfer of nanofluids in a lid-driven trapezoidal cavity. International Communications in Heat and Mass Transfer 77: 195-205. https://doi.org/10.1016/j.icheatmasstransfer.2016.08.01 0

[24] Cheng TS, Liu WH. (2014). Effects of cavity inclination on mixed convection heat transfer in lid-driven cavity flows. Computers \& Fluids 100: 108-122. https://doi.org/10.1016/j.compfluid.2014.05.004

[25] Ismael MA, Pop I, Chamkha AJ. (2014). Mixed convection in a lid-driven square cavity with partial slip. International Journal of Thermal Sciences 82: 47-61. https://doi.org/10.1016/j.ijthermalsci.2014.03.007

[26] Muthtamilselvan M, Doh DH. (2014). Mixed convection of heat generating nanofluid in a lid-driven cavity with 
uniform and non-uniform heating of bottom wall. Applied Mathematical Modelling 38(13): 3164-3174. https://doi.org/10.1016/j.apm.2013.11.033

[27] Kefayati GHR. (2016). Heat transfer and entropy generation of natural convection on non-Newtonian nanofluids in a porous cavity. Powder Technology 299: 127-149. https://doi.org/10.1016/j.powtec.2016.05.032

[28] Kefayati GHR. (2017). Mixed convection of nonNewtonian nanofluid in an enclosure using Buongiorno's mathematical model. International Journal of Heat and Mass $\quad$ Transfer 108: 1481-1500. https://doi.org/10.1016/j.ijheatmasstransfer.2016.12.103

[29] Kefayati GHR. (2017). Simulation of natural convection and entropy generation of non-Newtonian nanofluid in a porous cavity using Buongiorno's mathematical model. International Journal of Heat and Mass Transfer 112: 709-744.

https://doi.org/10.1016/j.ijheatmasstransfer.2017.04.121

[30] Hatami M, Song D, Jing D. (2016). Optimization of a circular-wavy cavity filled by nanofluid under the natural convection heat transfer condition. International Journal of Heat and Mass Transfer 98: 758-767. https://doi.org/10.1016/j.ijheatmasstransfer.2016.03.063
[31] Haddad OM, Alkam MK, Khasawneh MT. (2004) Entropy generation due to laminar forced convection in the entrance region of a concentric annulus. Energy 29: 35-55. https://doi.org/10.1016/S0360-5442(03)00156-7

[32] Klalkhali H, Faghri A, Zuo ZJ. (1999). Entropy generation in a pipe system. Appl. Therm. Eng. 19(10): 1027-1043. https://doi.org/10.1016/S1359 4311(98)00089-1

[33] Abu-Hijleh BAK, Abu-Qudais M, Abu-Nada E. (1999). Numerical prediction of entropy generation due to natural convection from a horizontal cylinder. Energy 24(4): 327-333. https://doi.org/10.1016/S03605442(98)00103-0

[34] Abu-Hijleh BAK, Heilen WN. (1999). Entropy generation due to laminar natural convection over a heated rotating cylinder. Int. J. Heat Mass Transfer 42(22): 4225-4233. https://doi.org/10.1016/S00179310(99)00078-2

[35] Mahmud S, Island AKS. (2003). Laminar free convection and entropy generation inside an inclined wavy enclose. Int. J. Therm. Sci. 42(8): 1003-1012. https://doi.org/10.1016/S1290-0729(03)00076-0 